\title{
Zur Kenntnis der Milben-Fauna von Bremen.
}

\author{
Von
}

Hans Voigts (Göttingen) und A. C. Oudemans (Arnhem). (Mit Taf. XII-XIX.)

\section{Vorbemerkung.}

In den Jahren 1901 und 1902 habe ich in meinem damaligen Wohnorte Oslebshausen neben anderen Arthropoden auch Milben gesammelt, deren Bestimmung Herr Dr. A. C. Oudemans gütigst ausgeführt hat; und es ist mir eine angenehme Pflicht, diesem ausgezeichneten Acarologen für seine liebenswürdige Mitarbeit auch an dieser Stelle herzlichst $\mathrm{zu}$ danken. Obgleich ich nur während der Universitätsferien (Ende März, Anfang April, August, September, Anfang bis Mitte Oktober) und, auch da nur während meiner freien Zeit sammeln konnte, so ist doch der Erfolg ein so guter, dass ich es wohl wagen darf, das Resultat schon jetzt zu veröffentlichen, zumal da eine zusammenfassende Arbeit über Bremer Milben noch nicht existiert, und ich die Sammeltätigkeit in dem in entomologischer Beziehung äusserst interessanten Bremer Gebiete leider habe aufgeben müssen. Der Vollständigkeit halber habe ich es vorgezogen, sämtliche bis jetzt in der näheren Umgebung von Bremen und bei Vegesack von den Herren Alfken und Poppe gesammelten Milben, wenigstens soweit sie durch die Literatur bekannt geworden sind, im Verzeichnis mit aufzunehmen, so dass es zugleich als Grundlage für weitere Forschungen dienen kann.

Während bisher meistens parasitisch lebende Milben bei Bremen gesammelt waren, habe ich besonders den unter Steinen, Holz, in Moos, Laub usw. freilebenden meine Aufmerksamkeit zugewandt. Zahlreiche und interessante Fänge machte ich hauptsächlich unter feuchtliegenden Ziegelsteinen, in deren Poren sich die Milben gerne aufhalten; und fast jedes noch so kleine Stückchen dieser Steine lieferte mir ein oder mehrere Exemplare. So habe ich manchmal stundenlang an ein und derselben Stelle Stein für Stein abgesucht, so dass ich schliesslich mit reicher Ausbeute versehen den Platz verlassen konnte. Es kann daher nicht genug empfohlen werden, bei entomologischen Exkursionen, besonders wenn es sich um das Sammeln winzig kleiner Tierchen handelt, eine bestimmte Stelle 
ziemlich lange und recht gründlich abzusuchen, anstatt nur hier und da einmal einen einzelnen Stein oder ein Holzstückchen usw. hochzuheben, was natürlich zwischendurch auch geschehen muss. Je länger der Sammler an einer bestimmten Örtlichkeit verweilt, und je genauer und gründlicher er diese untersucht, desto reichlicher wird er für seine Mühe belohnt werden. ${ }^{1}$ ) Als Beispiele führe ich nur folgende an:

Am 11. 4. 01 sammelte ich ungefähr 2 Stunden an der nalten ${ }^{*}$ Weser unter Steinen und erbeutete 15 Arten (1 nov. spec.) in 47 Exemplaren; am 26. 8. 01 im Hühnerhof unter altem Holz 11 Arten (1 nov. spec.) in ca. 70 Exemplaren; am 1. 9. 01 hinter der Anstaltsmauer unter feuchten Steinen 17 Arten (2 nov. spec.) in 35 Exemplaren; am 4. 9. 01 bei der Mühle unter Ziegelsteinen 17 Arten (1 nov. spec.) in 60 Exemplaren; am 9. 9. 01 im Hühnerhof unter Ziegelsteinen 15 Arten, darunter eine neue und eine seit 100 Jahren nicht wiedergefundene, in 62 Exemplaren usw. usw. Diese Beispiele zeigen zugleich, wie reich die Bremer Gegend an Milben ist, und es ist daher sehr zu wünschen, dass dem folgenden Verzeichnisse recht bald ein Nachtrag folgen möge!

Einige Bemerkungen über den Fang von Milben erlaube ich mir hier einzufügen. Man versehe sich mit einer genügenden Anzahl kleiner Röhrengläschen von 4-5 cm Länge und ea. $1 \mathrm{~cm}$ Durchmesser mit möglichst porenfreien Korken, und tue die Fänge an den verschiedenen Örtlichkeiten jedesmal in ein besonderes Glas; die Korken sind zu numerieren, und man führe ein Verzeichnis, in dem Fundort, Datum und etwaige Bemerkungen, die sich auf den Inhalt der einzelnen Gläschen beziehen, genau anzugeben sind. Man fängt die Milben am besten mit einem feinen spitzen Haarpinsel oder mit einer am Ende ziemlich spitz auslaufenden Vogelfeder, die man etwas in die Flüssigkeit eintaucht, und mit der dann die Tierchen aufgetupft werden. Da sehr viele Arten schnell laufen, so erfordert ihr Fangen immerhin erst einige Übung. Als Tötungswie Aufbewahrungsflüssigkeit gebrauchte ich stets die von Herrn Dr. Oudemans empfohlene Mischung, in welcher die Milben die Beine strecken und weich bleiben:

$$
\begin{array}{rll}
87 & \text { vol. T. Alkohol } 70 \% \\
5 & \% & \text { Glycerin } \\
8 & \Rightarrow & \text { Acid. Acet. glac. }
\end{array}
$$

Was nun meine Oslebshauser - einmal sammelte ich auch bei Oberneuland - Ausbeute betrifft, so beläuft sich die Zahl der gesammelten Arten auf 108, von denen einzelne schon vorher im Bremer Gebiete von Alfken oder Poppe gefunden waren. Als für die Wissenschaft neu ergaben sich 1 Gattung und 17 Spezies:

1) Vgl. auch über diesen Gegenstand: Friedr. Dahl, Fang von Spinnentieren, nichtfliegenden Insekten und anderen Gliederfüsslern in: Anleitung z. Samm, Konserv. und Verpacken von Tieren f. d. Zool. Mus. in Berlin. 2. Ausg., 1902, S. 35 ff. Hier ist auch eine übersichtliche Zusammenstellung der Fundorte gegeben. 
Parasitus bremensis, consanguineus, eta, consimilis, congener, beta, alpha, theta, zeta, setosus, consors; Pergamasus gamma; Eugamasus epsilon; Hypoaspis lubrica, Seiulus levis; Metaparasitus (nov. gen.) suboles; Uropoda levisetosa. Ausserdem erhielten neue Namen eine Gattung: Banksia für Kochia Oudms, welcher Name bereits anderweitig vergeben war, und eine Art: Eremaeus varius, welche bisher nur als eine Varietät angesehen wurde. Kurze Diagnosen der im folgenden ausführlich beschriebenen neuen Arten veröffentlichten wir bereits am 14. Juni d. J. im Zool. Anzeiger XXVII, S. 651-656. Hier teilten wir auch mit, dass bei der Mehrzahl dieser Arten eine genauere Fundorts- und Zeitangabe nicht gemacht werden konnte, da nach der vorläufigen Determination unter beieinander gebrachten Deutonymphen, Protonymphen und Larven, die fast alle als zu bereits bekannten Arten gehörig angesehen waren, diese nachträglich noch als novae species festgestellt wurden. Als besonders wertvollen Fund erwähne ich die seit 1804 nicht wiedergefundene Bryobia lapidum (Hammer).

Die Gesamtzahl der bis jetzt aus der näheren Umgebung Bremens und Vegesacks bekannten Milben beträgt 167 Arten, von denen die von mir nicht gefundenen 59. Arten von den Herren Poppe und Alfken von Fledermäusen, Maulwürfen, Mäusen, Vögeln, Insekten usw. gesammelt wurden; diese letzteren sind im Verzeichnisse mit einem $\dagger$ vor dem Namen versehen. Die Buchstaben A. und P. hinter den Fundortsangaben zeigen an, dass die betreffende Spezies von Alfken oder Poppe gesammelt wurde. Alle übrigen Angaben beziehen sich, falls kein anderer Ortsname angeführt, auf mein Sammelterrain Oslebshausen; und zwar habe ich bei jeder einzelnen Art das Vorkommen, die Anzahl der erbeuteten Exemplare nach ihren Eutwicklungsstadieu, sowie das Datum genau angegeben. Ebenso sind die betr. Angaben für die von Alfken und Poppe gefundenen Milben genau wiedergegebeu.

Fundortsangaben, Neubeschreibungen usw. vor Bremer Landmilben finden sich in folgenden Abhandlungen (die in Klammern gesetzten Daten geben die Zeit der Publikation an):

1. A. D. Michael, Über einige Abschnitte in der Entwicklungsgeschichte von Tegeocranus cepheiformis (Nic.): Abh. Nat. Ver. Bremen IX, P. 207 ff. (1885).

2. S. A. Poppe, Über parasitische Milben: ibid. X, p. $205 \mathrm{ff}$. (1888).

3. - Beitrag zur Kenntnis der Gattung Myobia v. Heyden: Zool. Anz. 19, p. 327 ff.; 337 ff. (1896)

4. A. C. Oudemans, A Sarcoptes of a Bat (Nyeteridocoptes poppei): Tijdschr. v. Entom. v. 40, p. 270 ff. (1. III. 1898).

5. - Further notes on Acari; 5. List of Acari coll by Mr. J. D. Alfken, of Bremen: ibid. v. 43, p. 114 f. (5. IX. 1900).

6. - - - ; 11. List of Acari collected by Mr. S. A. Poppe: ibid. v. 43, p 121 f. (5. IX. 1900).

7. - Notes on Acari 3 d series: Tijdschr. d. Ned. Dierk. Ver. (2) v. 7. p. 50 ff. (30. XI. 1901). 
8. A. C. Oudemans, Notes on Acari $4^{\text {th }}=$ series; 4. Acari of Germany: ibid. (2) v. 7, p. 277 f. (18. VII. 1902).

9. - Notes on Acari $7 \stackrel{\text { th }}{=}$ series: ibid. (2) v. 8, p. 17 ff. (31. X. 1902).

10. - Notes on Acari $8^{\text {th }}$ series; 1 . Acari of Germany; ibid. (2) v. 8, p. 70 ff. (10. XII. 1903).

11. H. Voigts und A. C. Oudemans, Neue Milben aus der Umgegend von Bremen: Zool. Anz. 27, p. 651-656 (14. VI. 1904).

12. A. C. Oudemans, Acariden von Borkum und Wangeroog. 1. Berichtigung: Abh. Nat. Ver. Brem. XVIII, 1., p. $77 \mathrm{f}$. (Das Separatum erschien im Sept. 1904).

Ausserdem finden sich mehrere Einzelangaben und Beschreibungen in „Entomologische Berichten“, herausgeg. von der Nederlandsche Entomologische Vereeniging, und in den „Verslagen“, die als Anhang zur Tijdschrift voor Entomologie erscheinen.

Da das Vorkommen der Mehrzahl der Milben an ganz bestimmte Ortlichkeiten gebunden ist, so halte ich es für nicht unwichtig, neben der systematischen Aufzählung der Arten auch eine nach Fundorten und Wirtstieren geordnete Zusammenstellung zu geben. Wie eine solche Übersicht einerseits ziemlich notwendig ist, um die auf einem bestimmten Tiere parasitierenden Milben kennen zu lernen, so dürfte sie anderseits auch mancherlei Interessantes in bezug auf das Vorkommen und die Verbreitung der frei umherlaufenden Arten bieten. Zugleich zeigt diese Übersicht einem künftigen Sammler, auf welche Örtlichkeiten er insonderheit noch sein Augenmerk zu richten hat, um ein möglichst vollständiges Bild der Bremer Milbenfauna geben $\mathrm{zu}$ können.

\section{A. Unter Steinen, Holz, in Moos usw.}

I. Unter Steinen, meist feuchtliegenden, besonders Ziegelsteinen :

a. an der „alten" Weser bei der kleinen Brücke (hinterm Adelenstift) [11. 4., 15. 4. 01]:

Parasitus coleoptratorum (L.), Pergamasus crassipes (L.), Uropoda ovalis (C. L. Koch), levisetosa Oudms. et Vgts., Thrombidium holosericeum (L.), Oribata clavipes (Herm.), Liacarus coracinus (C. L. Koch), Eremaeus bipilis (Herm.), similis (Mich.), varius Oudms. et Vgts., Banksia lata (Nic.), Scutovertex ovalis (Berl.), Notaspis gilvipes (C. L. Koch), orbicularis (C. L. Koch), trimaculata (C. L. Koch), humeralis Herm., elimata (C. L. Koch), lucasi (Nic.).

b. bei der (jetzt nicht mehr vorhandenen) Mühle, beim Adelenstift [4. 9. 01]:

Parasitus consanguineus Oudms. et Vgts., Pergamasus longulus (Oudms.), Asca togata (C. L. Koch), Uropoda ovalis (C. L. Koch), Poecilophysis celer (Herm.), pratensis (C. L. Koch), Eupodes striola C. L. Koch, Penthaleus haematopus C. L. Koch, minor (R. Can.), Bdella longicornis (L.), lapidaria Kram., capillata Kram., vulgaris 
(Herm.), silvatica Kram., Anystis baccarum (L.), Eremaeus lucorum (C. L. Koch), Notaspis lucasi (Nic.).

c. am Weserdeich [8. 9. 01]:

Macrocheles badius (C. L. Koch), Penthalodes ovalis (A. Dug.), Bdella silvatica Kram., Anystis baccarum (L.), Achorolophus ignotus (Oudms.).

d. hinter "Finkenau" (Steinhaufen) [24. 8. 01]; auf einem Hofe (Steinhaufen) [29. 9. 01]:

Eupodes striola C. L. Koch, Linopodes motatorius (L.).

e. hinter der Anstaltsmauer (zwischen dieser und dem Blocklande) $[1.9 ., 15.9 .01 ; 9.4 .02]$ :

Parasitus coleoptratorum (L.), affinis Oudms., consanguineus Oudms. et Vgts., setosus Oudms. et Vgts., Pergamasus crassipes (L.), septentrionalis (Oudms.), Trachygamasus pusillus (Berl.), Macrocheles badius (C. L. Koch), merdarius (Berl.), Gamasellus spinipes (Oudms.), Hypoaspis pavida (C. L. Koch), Euiphis halleri (G. et R. Can.), Uropoda ovalis (C. L. Koch), Cilliba vegetans (A. Dug.), Poecilophysis pratensis (C. L. Koch), Eupodes striola C. L. Koch, Linopodes motatorius (L.), Bdella longicornis (L.), Tetronychus telarius (L.), Camisia biverrucata (C. L. Koch), Eremaeus lucorum (C. L. Koch), similis (Mich.), varius Oudms. et Vgts., Cepheus coriaceus (C. L. Koch), Scutovertex ovalis (Berl.), Notaspis gilvipes (C. L. Koch), humeralis Herm., quadricornuta (Mich.), alata Herm., Pelops acromius (Herm.), Tyroglyphus putrescentiae (Schrk.), Anoetus berghi (Jens.).

f. Hühnerhof $[23.8 ., 9.9 .01 ; 16.9 .02]$ :

Parasitus crassus (Kram.), affinis Oudms., Pergamasus crassipes (L.), septentrionalis (Oudms.), Trachygamasus pusillus (Berl.), Eugamasus oudemansi Berl., Seiulus levis Oudms. et Vgts., Eupodes striola C. L. Koch, Penthaleus haematopus C. L. Koch, Bdella longicornis (L.), Bryobia lapidum (Hammer), praetiosa C. L. Koch, Cunaxa setirostris (Herm.), Thrombidium purpureum C. L. Koch, Achorolophus nemorum (C. L. Koch), Hermannia scabra (L. Koch), Oribata nitens (C. L. Koch), Eremaeus lucorum (C. L. Koch), varius Oudms. et Vgts., Scutovertex ovalis (Berl.), Notaspis humeralis Herm.

g. unter einem Blumentopfe im Hausgarten [27. 9. 02]: Anystis baccarum (L.).

b. ein näherer Fundort unbekannt bei den neuen Arten:

Parasitus bremensis, eta, consimilis, congener, beta, alpha, theta, zeta, consors, Pergamasus gamma, Eugamasus epsilon, Metaparasitus suboles.

II. Unter $\mathrm{Holz}$ (Brettern, Baumrinde usw.):

a. unter trockenen auf der Erde liegenden Brettern, Hühnerhof [26. 8., 15. 9. 01], Hausgarten [6. 10. 01]:

Parasitus coleoptratorum (L.), affinis Oudms., Pergamasus canestrinii (Berl.), Macrocheles badius (C. L. Koch), marginatus (Herm.), tridentinus (G. et R. Can.), Hypoaspis limbata (C. L. Koch), lubrica 
Oudms. et Vgts., Cilliba vegetans (A. Dug.), Cheletes eruditus (Schrk.), Aleurobius farinae (L.).

b. unter altem morschen Holz, Hühnerhof [23. 8. 01];

Linopodes motatorius (L.), Bimichaelia angustana (Berl.), Bdella longicornis (L.), Achorolophus nemorum (C. L. Koch).

c. unter trockener auf der Erde liegender Baumrinde, Sandberg [27. 9. 02], Oberneuland, Jürgens Holz (4 10. 01]:

Trachygamasus pusillus (Berl.), Euiphis ostrinus (C. L. Koch), Tydeus foliorum (Schrk.), Linopodes motatorius (L.), Anystis baccarum (L.), Cunaxa taurus (Kram.), Hypochthonius rufulus C. L. Koch, Liacarus subterraneus (C. L. Koch), Eremaeus varius Oudms. et Vgts., Hoploderma dasypus (A. Dug.).

d. unter der Rinde von Abies excelsa, Badener Berge bei Achim [5. 4. 01] A.:

Allothrombidium fuliginosum (Herm.), Erythraeus regalis

(C. L. Koch).

unter der Rinde von Quercus robur, Bremen, Bürgerpark A.: Notaspis humeralis Herm.

e. unter faulendem $\mathrm{Holz}$ und Blättern, hinter „Finkenau“ [24. 8. 01], Hühnerbof [10.9. 02]:

Parasitus coleoptratorum (L.), affinis Oudms., Pergamasus crassipes (L.), Cyrtolaelaps nemorensis (C. L. Koch), Hypoaspis limbata (C. L. Koch), Eupodes striola C. L. Koch, Bdella longicornis (L.), Oribata clavipes (Herm.), Tyroglyphus putrescentiae (Schrk.).

III. In feuchtem Moos, am Grunde von Melchers Mauer [16. 4. 01], Hausgarten [20. 4. 01]:

Parasitus coleoptratorum (L.), affinis Oudms., Pergamasus longulus (Oudms.), Hypoaspis pavida (C. L. Koch), Bdella capillata Kram., Anystis baccarum (L.), Tarsotomus comes Berl.

IV. Aus einem Unkrauthaufen gesiebt, vorm Blocklande [21.9. 01]:

Parasitus coleoptratorum (L.), lunaris (Berl.), affinis Oudms., Macrocheles badius (C. L. Koch), Uropoda ovalis (C. L. Koch), Eupodes striola C. L. Koch, Anystis baccarum (L.), Notaspis lucasi (Nic.).

V. Aus Heu gesiebt, am Grunde einer Heudieme vorm Blocklande [30.9. 01$]$ :

Parasitus lunaris (Berl.), affinis Oudms., Asca peltata (C. L. Koch), Uropoda ovalis (C. L. Koch), Bdella lapidaria Kram., Cyta latirostris (Herm.), Anystis baccaruni (L.), Cheletes venustissimus C. L. Koch, Belaustium miniatum (Herm.).

VI. Aus Anspülicht („Schlick“) gesiebt, an der "alten“ Weser [19. 9. 01]:

Parasitus affinis Oudms., Seiulus hirsutus (C. L. Koch), levis Oudms. et Vgts., Eupodes striola C. L. Koch, Bdella capillata Kram., Anystis baccarum (L.), Scutovertex ovalis (Berl.), Notaspis trimaculata (C. L. Koch), -Tyroglyphus putrescentiae (Schrk.). 
VII. Von Gras gestreift, vorm Blocklande [21. 9. 01]:

Bdella vulgaris (Herm.), Anystis baccarum (L.), Bryobia praetiosa C. L. Koch, Notaspis trimaculata (C. L. Koch).

VIII. Auf der Unterseite von Himbeer-, Kirschen-, Rosenblättern: an trockenem und faulendem Gurken-, Bohnenkraut; Hausgarten [17. 9. 01; 16. 9., 3. 10. 02];

Tetronychus telarius (L ).

Auf Spargelkraut (Asparagus sprengeri), Wohnzimmer [12.4. 02]:

Tetronychus telarius (L.), Bryobia praetiosa C. L. Koch.

IX. An Knochen, hinter der Anstaltsmauer [20. 3. 02]:

Poecilochirus fimetarius (J. Müll.).

An trockenen Feigen [Sept. 01]:

Melichares agilis Her.

An altem Rahmkäse [28. 10. 02]:

Tyroglyphus putrescentiae (Schrk.), Aleurobius farinae (L.), Glycyphagus domesticus (Deg.).

An Schinken (Vegesack P.):

Tyroglyphus putrescentiae (Schrk.).

In pulverisiertem Eidotter (Vegesack P.):

Aleurobius farinae (L.).

An Kürbis-Marmelade (Vegesack P.):

Carpoglyphus passularum (Her.).

In Mehl (Vegesack P.):

Glycyphagus setosus (C. L. Koch).

In Möbeln (an der Rosshaarausfüllung) (Bremen P.):

Glycyphagus domesticus (Deg.), fustifer Oudms.

In einer Schachtel mit lnsekten-Detritus (Bremen A):

Glycyphagus domesticus (Deg.).

\section{B. Auf Tieren.}

NB. Falls eine Art auch oder nur im Neste des betr. Tieres gefunden wurde, habe ich es hinter dem Namen bemerkt.

I. Vertebrata.

\section{Mammalia.}

a. Chiroptera.

Plecotus auritus . . . Liponyssus musculi (C. L. Koch), lepidopeltis Klti., lobatus Klti., Spinturnix plecoti Oudms., Allothrombidium fuliginosum (Herm.).

Vesperugo noctula. . . Liponyssus lobatus Klti., Spinturnix carnifex (C. L. Koch), Argas vespertilionis (Latr.). 
Vesperugo pipistrellus

serotinus

Vespertilio murinus

Sorex vulgaris

Talpa europaea .

Sciurus vulgaris Mus decumanus (Oudms.).

\section{b. Insectivora.} (Mich.).

c. Rodentia.
Liponyssus musculi (C. L. Koch), lepidopeltis Klti, lobatus Klti., kolenatii Oudms, Anystis baccarum (L.), Nanacarus minutus (Oudms.), Glycyphagus cadaverum (Schrk.), Prosopodectes chiropteralis (Trt.).

Euiphis halleri (G. et R. Can.), Liponyssus musculi (C. L. Koch), Spinturnix vespertilionis (L.), Argas vespertilionis (Latr.), Cunaxa setirostris (Herm.), Nanacarus minutus (Oudms.), Glycyphagus cadaverum (Schrk.), Prosopodectes chiropteralis (Trt).

Liponyssus arcuatus (C. L. Koch), lepidopeltis Klti., Spinturnix vespertilionis (L.), Prosopodectes poppei

Myobia claparedei Poppe, elongata Poppe, Tarsonemus soricicola Oudms., Nanacarus minutus (Oudms.), Labidophorus talpae Kram., Glycyphagus domesticus (ieg.), Anoetus spiniferus

Parasitus lunaris (Berl.) [Nest], Eugamasus cornutus (G. et R. Can.) [Nest], oudemansi Berl. [auch im Nest], Euryparasitus terribilis (Mich.) [Nest], Macrocheles tridentinus (G. et R. Can.) [Nest], Haemogamasus hirsutus Berl. [auch im Nest], michaeli Oudms., Hypoaspis arcualis (C. L. Koch) [auch im Nest], talpae Oudms., Liponyssus albatus (C. L. Koch), Asca affinis Oudms., Myobia brevihamata Haller, Allothrombidium fuliginosum (Herm.), Pygmephorus spinosus Kram., Notaspis lucasi (Nic.) [Nest], Labidophorus talpae Kram., platygaster (Mich.) [Nest], Glycyphagus domesticus (Deg.).

- Listrophorus pagenstecheri Haller.

Myobia ensifera Poppe, Notoedres muris (Mégn.). 
Mus musculus

, silvaticus
Hypoaspis limbata (C. L. Koch), Myobia musculi (Schrk.), affinis Poppe, Myocoptes musculinus (C. L. Koch).

Parasitus coleoptratorum (L.), poppei Oudms., Haemogamasus michaeli Oudms., Laelaps agilis C. L. Koch, Hypoaspis arcualis (C. L. Koch), Ixodes ricinus (L.), Myobia musculi (Schrk.), lemnina (C. L. Koch), Allothrombidium fuliginosum (Herm.), Pygmephorus spinosus Kram., Glycyphagus cadaverum (Schrk.).

" minutus. . . . Laelaps agilis C. L. Koch [Nest], Liponyssus chelophorus Oudms. [Nest], cadaverum (Schrk.) [Nest].

\section{Arvicola glareolus} Parasitus coleoptratorum (L.), Dermacarus arvicolae (Duj.).

amphibius . . Listrophorus leuckarti Pgst.

arvalis .

Laelaps agilis C. L. Koch, Hypoaspis limbata (C. L. Koch), arcualis (C. L. Koch), Liponyssus albato-affinis Oudms., Myobia lemnina (C. L. Koch), Dermacarus arvicolae (Duj.).

\section{Aves. \\ a. Pici.}

Picus viridis. . . . . Syringophilus bipectinatus Heller.

b. Passeres.

Serinus canarius Dermanyssus gallinae (Deg.).

Fringilla coelebs

Passer domesticus .

Hirundo riparia.

Troglodytes parvulus

Turdus pilaris

Parus caudatus .

Garrulus glandarius

Perdix cinerea

Syringophilus bipectinutus Heller.

Gallus domesticus

Anas boschas.
Larus argentatus

Pseudalloptes bisubulatus (Rob.), Megninia cubitalis (Mégn.). 


\section{Arthropoda.}

\section{Coleoptera.}

Carabus cancellatus . . .
monilis . . Gamasoides fucorum (Deg.).

Staphylinide . . . . . Seiulus hirsutus (C. L. Koch).

Necrophorus humator. . . $\begin{aligned} & \text { Gamasoides subterraneus (J. Müll.), } \\ & \text { fucorum (Deg.), Macrocheles marginats }\end{aligned}$ "vespillo . . (Herm.), Neoseius novus (Oudms.), Anoetus neglectus Oudms.

Aphodius fimetarius . . . Parasitus affinis Oudms., Macrocheles badius (C. L. Koch), Euiphis halleri (G. et R. Can.), Cilliba vegetans (A. Dug.), Anoetus fimetarius (Can. et Berl.).

" inquinatus . . . Euiphis halleri (G. et R. Can.).

" arenarius . . . Macrocheles subbadius (Berl.).

Geotrupes stercorarius . Cilliba vegetans (A. Dug.).

Athous haemorrhoidalis . . Belaustium murorum (Herm.).

Criocephalus ferus. . . . Polyaspis patavinus G. et R. Can., Uropoda ovalis (C. L. Koch).

\section{Hymenoptera.}

Bombus terrestris . . . Pergamasus bomborum (Oudms.), $\boldsymbol{B} y$ " hortorum . . . . poaspis fuscicolens Oudms., Disparipes Psithyrus vestalis . . . . bombi Mich.

Prosopis brevicornis. . . Uropoda alfkeni Oudms.

Stelis phaeoptera . . . . Trichotarsus intermedius Oudms.

\section{Diptera.}

Musca domestica . . . Macrocheles marginatus (Herm.).

4. Arachnoidea.

Opilio serripes etc. . . . Achorolophus ignotus (Oudms.).

Schliesslich gebe ich noch eine Liste der von mir an verschiedenen Örtlichkeiten gefundenen Milbenarten, und zwar mit Angabe des Vorkommens in den verschiedenen Fängen und der Anzahl der erbeuteten Exemplare. Was die Fänge betrifft, so diene folgendes Beispiel als Erläuterung:

Parasitus coleoptratorum (L.) fand sich unter Steinen, und zwar von 13 Fängen (zu verschiedenen Zeiten) in 3 Fängen in 4 Exemplaren, etc. 


-

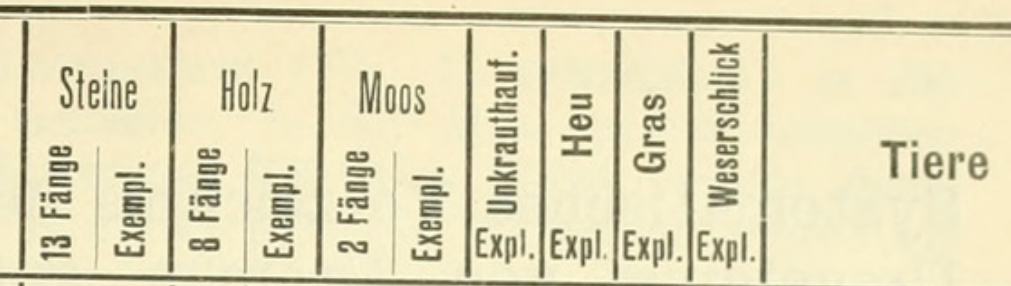

Parasitus coleoptratorum (L.) .. .

", lunaris (Berl.)

" affinis Oudms.

Pergamasus longulus (Oudms.).

"

crassipes (L.)

Trachygamasus pusillus (Berl.)

Macrocheles badius (C. L. Koch)

Hypoaspis limbata (C. L. Koch) .

pavida (C. L. Koch)

Seiulus levis Oudms. et Vgts. . .

Uropoda ovalis (C. L. Koch) . .

Cilliba vegetans (A. Dug.)

Eupodes striola C. L. Koch .

Linopodes motatorius (L.)

Bdella longicornis (L.) .

" lapidaria Kram.

" capillata Kram. .

Anystis baccarum (L.) .

Tetronychus telarius (L.).

Bryobia praetiosa C. L. Koch. . .

Achorolophus nemorum (C. L. Koch)

ignotus (Oudms.). .

Oribata clavipes (Herm.) . . . .

Eremaeus varius Oudms. et Vgts.

Scutovertex ovalis (Berl.). . . .

Notaspis trimaculata (C. L. Koch)

" humeralis Herm. . . .

Tyroglyphus putrescentiae (Schrk.)

Tyroglyphus putrescentiae (Schrk.)
Aleurobius farinae (L.) . . . . .
Glycyphagus domesticus (Deg.)

\begin{tabular}{|c|c|c|c|c|c|c|c|c|}
\hline 4 & 3 & 22 & 2 & 14 & - & - & - & - \\
\hline$\overline{1}$ & $r$ & - & - & - & 7 & - & - & - \\
\hline 11 & 5 & 25 & 1 & 8 & 1 & 1 & - & Aphodius fimetarius \\
\hline 1 & - & - & 1 & 1 & $-1-1$ & - & - & - \\
\hline 15 & 1 & 1 & - & - & $-1-$ & - & - & - \\
\hline 46 & 1 & 1 & - & - & $-1-1$ & -1 & - & - \\
\hline 2 & 2 & 21 & - & - & $1 \mid-$ & - & - & Aphodius \\
\hline- & 2 & 6 & - & - & $-1-1$ & -1 & - & 12 \\
\hline 1 & - & - & 1 & 2 & $-1-$ & -1 & - & - \\
\hline 1 & - & - & - & - & $-1-$ & -1 & 4 & - \\
\hline 27 & - & - & - & - & \begin{tabular}{l|l}
1 & 1
\end{tabular} & - & - & Criocephalus ferus (6 \\
\hline 9 & 2 & 3 & - & - & $-1-1$ & -1 & - & $\begin{array}{l}\text { Aphodi } \\
\text { Geotrul }\end{array}$ \\
\hline 14 & 1 & 1 & - & - & $1 \mid-$ & -1 & 2 & - \\
\hline 16 & 2 & 11 & - & - & $-1-1$ & -1 & - & - \\
\hline 20 & 2 & 8 & - & - & $-1-1$ & -1 & - & - \\
\hline 1 & - & - & - & - & $\begin{array}{ll}-4 \\
-4\end{array}$ & - & -1 & - \\
\hline 1 & - & - & 1 & 1 & $-1-1$ & - & 16 & - \\
\hline 4 & 1 & 2 & 1 & 2 & \begin{tabular}{l|l}
1 & 1
\end{tabular} & 4 & 7 & - \\
\hline 1 & - & - & - & -1 & $-1-$ & - & - & Unters. v. Rosel \\
\hline 15 & - & - & - & - & $-1-1$ & 11 & - & Asparagus sprengeri ( \\
\hline 1 & 1 & 2 & - & - & $-1-1$ & -1 & - & - \\
\hline 1 & - & - & - & - & $-1-1$ & - & - & pilio (55) \\
\hline 2 & 1 & 2 & - & - & $-1-1$ & -1 & - & - \\
\hline 3 & 1 & 1 & - & - & $-1-1$ & - & - & - \\
\hline 4 & - & - & - & - & $-1-1$ & -1 & 1 & - \\
\hline 1 & - & - & - & - & $-1-1$ & 1 & 1 & - \\
\hline 21 & 1 & $\infty$ & - & -1 & $-1-1$ & - & - & - \\
\hline 6 & - & - & - & $-i$ & $1 \mid-$ & $1-$ & -1 & Talpa europaea (Nest) \\
\hline 8 & $\begin{array}{l}1 \\
1\end{array}$ & 1 & & t. Rahm & nk. u. Schink & & 1 & - \\
\hline & & & & & & & & vulgaris \\
\hline
\end{tabular}

Göttingen, Oktober 1904.

H. Voigts. 
Systematisches Verzeichnis der in der näheren Umgebung von Bremen gefundenen Milben, nebst Beschreibung neuer Arten.

NB. Lv. = Larva, Nph. = Nympha, Prot. = Protonympha, Deut. = Deutonympha.

\section{Parasitidae.}

Parasitinae.

Parasitus Latr.

$\dagger$ 1. P. poppei Oudms.

Vegesack: auf Mus silvaticus (Deut.) P.

\section{P. coleoptratorum (L.).}

Unter feuchten Steinen: an der "alten“ Weser bei der Brücke (1 Deut.) 11. 4. 01; hinter der Anstaltsmauer (1 Lv., 1 Deut.) 15. 9.01 (1 Deut.) 9. 4. 02. Unter Holz: im Hühnerhof (1 Lv., 2 Prot., 9 Deut., 2 o, 1 f) 26. 8. 01, (3 Deut.) 15. 9. 01. Unter faulendem Holz und Blättern: im Hühnerhof (2 Deut., 2 q) 10. 9. 02. - In Moos: am Grunde von Melchers Mauer (5 Deut.) 16. 4. 01; Hausgarten (1 Deut., 8 Prot.) 20. 4. 01. - Aus einem Unkrauthaufen gesiebt: vorm Blocklande (1 Deut.) 21. 9. 01.

Fuchsberg b. Vegesack: auf Arvicola glareolus Juni. P. Vegesack: auf Mus silvaticus P.

3. P. crassus (Kram.).

Unter Ziegelsteinen im Hühnerhof (1 f) 9. 9. 01.

4. P. bremensis Oudms. et Vgts.

(Taf. XII, Fig. 1-9.) 1904).

P. bremensis Oudms. et Vgts: Zool. Anz. 27, p. 651 (14. 6.

Weibchen. Länge: 1650-1710 $\mu$. Farbe, Textur und Gestalt wie die des + von $P$. coleoptratorum (L.); der Leib ist lederartig.

Rückenseite (Fig. 1) mit zwei Schildern, welche 805, resp. $735 \mu$ lang sind und ein ziemlich breites Band von weicher Haut zwischen sich lassen. Vorderschild hinten konvex; Hintersehild vorn ein wenig konkav, von einem ziemlich gleichbreiten Saum von weicher Haut umgeben, also viel mehr nach hinten sich erstreckend als bei der Vergleichsspezies. Haare der Schilder in gewöhnlicher Zahl und Anordnung, alle mehr oder weniger stäbchenartig; die 4 Paar längeren Borsten des vorderen Schildes deutlich distal ein wenig verdickt und behaart (Fig. 3 und 4). Peritrematalschilder vor den Schultern sichtbar, nicht mit dem Vorderschilde verwachsen. 
Bauchseite. Tritosternum (Fig. 5) gewöhnlich; in der distalen Hälfte plötzlich schmäler; in der Mitte mit 2 seitlichen kleinen dreieckigen durchsichtigen Blättchen, distal ebenso; distal verlängert in zwei kleine länglich-viereckige Stückchen, welche die gefiederten Zipfel tragen und deutlich sowohl mit dem Stamme als mit den Zipfeln Gelenke bilden; Zipfel normal. Jugularschilder (Fig 2) klein, L-förmig; ein zweites Paar linienförmig, lang, transversal. Sternal- und innerer Teil der Pedalschilder verwachsen, breit, mit den gewöhnlichen 3 Paar Sternalhaaren, vorn konvex. Metasternalschilder gewöhnlich, kaum vom Sternalteile geschieden, mit dem gewöhnlichen Paare Metasternalhaare. Genitalschild von gewöhnlicher Gestalt, kaum vom Ventralschilde geschieden, mit dem gewöhnlichen Paare Genitalhaare. Ventral-, Anal-, Inguinal-, Peritrematal- und äusserer Teil der Pedalschilder verwachsen, mit ungefähr 12 Paar Borsten am ventralen Teile. Peritremata über den Coxae I endend. Anus elliptisch. Cribrum gross. Fig. 6 stellt ein Haar im weichen Hautsaum seitlich vom Ventralschilde dar.

Epistom (Fig. 4) nur im hinteren Teile von den Seitenteilen des Capitulums durch eine feine Linie geschieden und hier mit einer transversalen accoladeförmigen ( $\longrightarrow$ ) feinen Linie versehen, die sich über die seitlichen Teile fortsetzt. Vorspringender Teil dreieckig mit breit-Haschenförmiger Mittelspitze, hinter welcher die Kanten fein gezähnelt sind. Die vordersten dieser Zähnchen länger als bei P. coleoptratorum (L.). Styli normal.

Mandibeln, wenn ganz eingezogen, ein wenig an dem zweiten Paare von stabförmigen grossen Rückenhaaren vorbeigehend (Fig. 1, punktierte Linie). Scheren (Fig. 7) mit den beiden Sinnesorganen, mit deutlicher Grenze zwischen Tibia und Basitarsus ein wenig vor dem hinteren Sinnesorgane. Hieraus lässt sich der Schluss ziehen, dass das hintere Sinnesorgan der Tibia angehört, so dass man ein tibiales und tarsales Sinnesorgan unterscheiden kann. Oberkiefer oder Basitarsus mit 2 kleinen dreieckigen Schneidezähnen vor dem Sinuesorgane, mit einem ebenso geformten Eckzahn hinter dem Sinnesorgane, mit einem zweiten langen blattförmigen Eckzahne und einem vorn abgerundeten blattförmigen Backenzahne. Unterkiefer oder Telotarsus mit 3 sehr kleinen Schneidezähnen hinter dem grossen, und 2 Eckzähnen; alle Zähne hinter dem vordersten sind nach hinten gerichtet. Pulvillum: eine Reihe von Haaren.

Maxillen. Hypostom (Fig. 5) seitlich mit mehr oder minder ovalen Vertiefungen versehen, welche hinter Haar IV ein Netzwerk bilden. Mittelfeld breit, deutlich von deu seitlichen Feldern geschieden, mit ungefäbr 12 Querreihen winziger dreieckiger Zähnchen, von welchen die zwei vordersten Reihen nach vorne und die drei hintersten nach hinten konvex sind. Vorderteil mit der gewöhnlichen medianen Grube, normalen Höruern, langen internen durchsichtigen Zipfeln und normaler fächerförmiger Franse. Palpen schlanker als 
bei $P$. coleoptratorum (L.). Dorsal (Fig. 1) hat der Femur proximal das gewöhnliche nach innen und vorn gebogene Haar, distal und intern den gewöhnlichen kleinen durchsichtigen daumenförmigen Anhang. Ventral (Fig. 8): Trochanter proximal und intern mit einem chitinösen dreieckigen Auswuchse, vor diesem mit einem kleineren mehr oder minder S-förmigen, und mit den gewöhnlichen zwei Borsten. Femur extern, ziemlich proximal mit der gewöhnlichen Borste, intern mit dem gewöhnlichen platten, durchsichtigen Haare, welches in drei Teile gespalten ist; der Vorderteil ist messerförmig, mit der Schneide nach vorn; der Mittelteil borstenförmig und kleiner; der Hinterteil borstenförmig und noch kleiner. Genu intern mit den gewöhnlichen messerförmigen Haaren; Tibia und Tarsus normal.

Beine (Fig. 1) schlank, ungefähr 1740, resp. 1110, 1290 und $1950 \mu$ lang. Ausser am Tarsus I sind alle Haare mehr oder weniger stäbchenförmig, und die grösseren mehr oder weniger keulenförmig und in ihrer distalen Hälfte behaart, hauptsächlich an Tibia IV und Tarsus IV. Praetarsus IV (Fig. 9) vollkommen dem des P. coleoptratorum (L.) gleich.

Fundort: Unter Steinen (ㅇ). - Type in coll. Oudemans. -

\section{P. lunaris (Berl.).}

Vorm Blocklande aus einem Unkrauthaufen gesiebt (7 Deut.) 21. 9. 01; ebenda, aus Heu gesiebt am Grunde einer Heudieme (2 Deut.) 30. 9. 01. -

Vegesack: Nest von Talpa europaea. März. P.

6. P. affinis Oudms.

Unter feuchten Steinen: hinter der Anstaltsmauer (1 Deut.) 1. 9. 01, (9 Deut.) 15. 9. 01; Hühnerhof (1 Deut.) 9. 9. 01. In feuchtem Moos: am Grunde von Melchers Mauer (1 Prot., 7 Deut.) 16. 4. 01. - Unter auf der Erde liegendem Holz: Hühnerhof (2 Prot., 10 Deut., 2 ऽ) 26. 8. 01, (1 Deut.) 15. 9. 01; Hausgarten, unter einem Brett (1 Deut.) 6. 10. 01. - Unter faulendem Holz und Blättern, hinter Finkenau (2 Deut.) 24. 8. 01; Hühnerhof (6 Deut., 1 ㅇ) 10.9.02. An der "alten" Weser aus Anspülicht gesiebt (1 Deut.) 19. 9. 01. - Vorm Blocklande, aus einem Unkrauthaufen gesiebt (1 Deut.) 21. 9. 01; ebenda aus Heu gesiebt am Grunde einer Heudieme (1 Deut.) 30. 9. 01. - Im Blockland: an Aphodius fimetarius (4 Deut.) 13. 4. 02.

7. P. consanguineus Oudms. et Vgts.

(Taf. XII, Fig. 10-16; Taf. XIII, Fig. 17-21.) (14. 6. 1904).

P. consanguineus Oudms et Vgts.: Zool. Anz. 27, p. 651

Männchen. Länge $880 \mu$. Farbe: wie gewöhnlich. Gestalt: von $P$. affinis Oudms. Textur: geschuppt auf den Schildern; fein gefurcht in den weichen Teilen.

Rückenseite (Fig. 10) mit zwei Schildern, welche 462, resp. $418 \mu$ lang sind. Vorderschild mit den gewöhnlichen 
Haaren, von denen die folgenden zu erwähnen sind. 4 nach vorn gerichtete Verticalhaare, das mediane Paar derselben ist kräftiger. An jeder Schulter eine starke glatte Borste. Zwischen diesen Schulterborsten und etwas mehr nach vorne ein Paar starke Borsten, welche ebenso weit voneinander als von den Schulterborsten entfernt sind. Auf der hinteren Hälfte des Schildes ein Paar starke Borsten, ungefähr ebenso weit voneinander entfernt. Ein wenig hinter jeder Schulterborste eine kleinere, gerade an der Leibeskante. Die übrigen Haare sind kleine Borsten und stehen an den gewöhnlichen Stellen. Das hintere Schild mit ein Paar langen Borsten in den Vorderecken und 6 ebensolchen auf der hinteren Hälfte. Am Rande zwei Reihen von Borsten, die etwas kleiner sind als die beschriebenen, und gerade an der Kante des Leibes ringsum eine Reihe von sehr kleinen Borsten. Die übrigen Haare an den gewöhnlichen Stellen; die in der Mitte des Schildes sind sehr klein.

Bauchseite (Fig. 11). Tritosternum (Fig. 12) kurz, sehr breit, ist ein niedriges Dreieck und berührt den chitinösen Ring um die Genitalöffnung. Die fiederförmigen Verlängerungen normal. An jeder Seite des Tritosternums findet sich ein noch niedrigeres Dreieckchen, welches als Jugular-Schildchen anzusehen ist. Alle übrigen Sekundärschilder miteinander verwachsen (Fig. 11), selbst mit den beiden Dorsalschildern. Sternometasternalteil breit, mit den gewöhnlichen 8 Haaren. Zwischen Coxae IV ein Paar Borsten; hinter Coxae IV ein Paar winzig kleiner Borsten. Etwas weiter nach hinten ein Paar Borsten. Noch weiter nach hinten, ungefähr in der Mitte des Bauches eine Reihe von 2 Paar, und noch weiter dahinter wieder eine Reihe von 2 Paar Borsten. Die zwei Haare zur Seite der Analöffnung sind sehr klein, aber das Postanalhaar ist eine lange Borste. Zwei andere lange Borsten finden sich an jeder Seite der Analöffnung. Am Rande entlang eine Reihe von 6 Paar kleiner Borsten. - Cribrum terminal. Stigmata an den gewöhnlichen Stellen. Die Peritremata enden über den Coxae I, sie liegen über Coxae II auf dem Rücken (Fig. 10).

Epistom (Fig. 13) mit 3 Spitzen; die Spitzen sind lang, dreieckig, sie können distal zwei oder drei kleinere Spitzchen tragen.

Mandibelṇ kurz; wenn ganz eingezogen, erreichen sie fast das Sternalschild. Scheren (Fig. 14) kurz und kräftig. Oberkiefer (distale Hälfte des Tibiotarsus) mit kräftigem distalen Schneidezahn; ein niedriger, breiter und stumpfer zweiter Schneidezahn, über welchem sich das Sinnesorgan befindet; und ein starker Eckzahn; keine Backenzähne. Unterkiefer (Telotarsus) mit starkem distalen Schneidezahn; eine Andeutung eines zweiten Schneidezahns; keine Eck- und Backenzähne. Copulationsorgan lang, stabförmig, gebogen, nach hinten gerichtet, an die Unterseite des Unterkiefers angeschmiegt, ebenso lang wie dieser. An der Aussenseite des 
Oberkiefers, weit nach hinten, ein durchsichtiges, plattes, lanzettförmiges Sinnesorgan. An der Bauchseite, bei der Ansatzstelle des Unterkiefers ein nicht sehr langes Pulvillum.

Maxillen. Die Hörner des Hypostoms (Fig. 12) auf langen Stielen, klein, gelb; auf diesen Stielen die 3 gewöhnlichen Haare. Die inneren Malae bilden zusammen ein hohes Trapezium, welches in zwei langen durchsichtigen Zipfeln endet; das Trapezium und die proximalen Hälften der Zipfel schön gefranst. Palpen mit folgenden Besonderheiten: Femur dorsal und an der Innenseite mit einem kleinen durchsichtigen Dorne (Fig. 10); ventral und an der Innenseite (Fig. 15) mit einem tiefgespaltenen messerförmigen Haare; Genu intern mit zwei messerförmigen Haaren, distal gerundet; Tarsus mit dem gewöhnlichen dreispaltigen Haare.

Beine. Beine I und IV ungefähr so lang wie der Körper; Beine II und III viel kürzer. Bein I, III und IV schlank, II ungefähr doppelt so dick. Bein II (Fig. 16): Femur mit deutlichem Basifemur und einem stumpfen Anhange oder Dorne, neben welchem zwei kleinere Höcker, einer hinter und einer vor dem Dorne; Genu mit zwei Höckern; Tibia distal ebenso; Tarsus mit deutlichem Basitarsus und distal mit 3 (wovon eins an der Aussenseite, nicht in der Figur angegeben) kleinen dornförmigen Haaren; Praetarsus ziemlich lang, proximal mit einem durchsichtigen Haare, distal mit einem kleineren ebensolchen. Klauen und Haftscheibe an allen Beinen ziemlich klein. Basifemur IV dorsal mit langer Borste.

Weibchen. Länge: $1040 \mu$. Farbe und Gestalt wie beim $\sigma^{\top}$; eines der beiden $q$ ist jedoch grasgrün. Textur wie beim 0 .

Rückenseite (Fig. 17) von zwei Schildern gedeckt, welche 484, resp. $596 \mu$ lang sind, so dass bein $q$ das hintere Schild länger ist als das vordere, im Gegensatz zum o. Die Haare wie beim 07 .

Bauchseite. Tritosternum (Fig. 19) gewöhnlich. Jugularschilder gewöhnlich. Sternalschild (Fig. 18) länger als breit, am Hinterrande mit einem untiefen dreieckigen Ausschnitt, dessen Spitze auf einer Linie liegt, welche $z$ wischen den Coxae II und III verläuft; mit den gewöhnlichen 3 Paar Sternalhaaren. Das erste Sternalhaaren-Paar ist distal gespalten (Fig. 19), mit weit divergierenden Ästen; das zweite Paar distal plötzlich umgebogen. Metasternalschilder gewöhnlich, hinten weit über dem Genitalschilde liegend (nicht in der Figur angegeben). Genitalschild gewöhnlich, weit nach hinten mit ein Paar Haaren. Ventral-

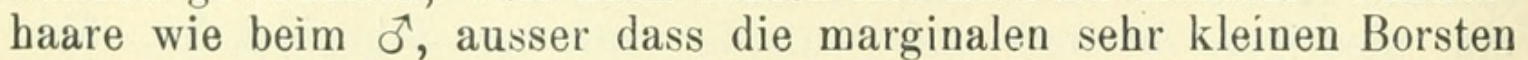
in der weichen Haut stehen. Ventral-, Anal- und Peritrematalschilder miteinander verwachsen, die letzteren vorne selbst mit dem vorderen Rückenschilde (Fig. 17). Stigmata und Peritre mata wie beim $0^{\top}$.

Epistom (Fig. 20) dreispitzig; die Spitzen dreieckig, lang, mit spitzen Enden. 
Mandibeln schlanker und ein wenig länger als beim $\sigma^{\star}$. Scheren (Fig. 21) vielzähnig. Oberkiefer mit 3 Schneidezähnen und 4 Eckzähnen; keine Backenzähne. Unterkiefer mit 1 Schneidezahn und 3 Eckzähnen; keine Backenzähne. An den mit einem + bezeichneten Stellen ist der Oberkiefer an der Aussenseite mit je einem Sinnesorgan versehen, welche kleiner als beim $\sigma^{\pi}$ sind. Pulvillum: ein Büschel von 12 divergierenden Haaren.

Maxillen. Hörner des Hypostoms (Fig. 19) länger als beim $\widehat{\sigma}$, und normaler gebaut; sie stehen auf starken Chitinisierungen, welche die „Stiele“ der männlichen Hörner nachahmen. Kein medianes Trapezium, wie es das of besitzt. Nur die Basis der mittleren Zipfel mit seitlicher Franse. Palpen wie beim ऽే.

Beine wie beim $\sigma^{\top}$, natürlich ausser den Beinen II, welche nur ein wenig dicker sind als die übrigen Beine.

Fundort: unter feuchten Steinen: hinter der Anstaltsmauer (1 ô, 1 ㅇ) 1. 9. 01; bei der Mühle (1 ㅇ) 4.9.01. - Typen in coll. Oudemans.

\section{P. eta Oudms. et Vgts.}

(Taf. XIII, Fig. 22-28.)

P. eta Oudms. et Vgts.: Zool. Anz. 27, p. 652 (14. 6. 1904).

Deutonympha. Länge: $672 \mu$. Farbe und Textur gewöhnlich. Gestalt wie die der Deuton. des Par. affinis Oudms.

Rückenseite (Fig. 22) mit zwei Schildern. Vorderschild hinten in der Mitte fast gerade, seitwärts etwas konvex; hinten nicht ganz rund, aber ziemlich zugespitzt, so dass es fast fünfeckig ist mit gerundeten Seiten und Ecken. Peritrematalschilder vor den Schultern sichtbar. Die Haare sind Borsten in gewöhnlicher Zahl und Stellung. Bemerkenswert sind die folgenden starken und langen Borsten: 2 Verticalhaare, 2 Schulterhaare, 2 auf der vorderen und 2 auf der hinteren Hälfte des Vorderschildes, und 4 im Hintersaum des Hinterschildes; auch in der weichen Haut um dieses Schild zwei Reihen von Borsten.

Bauchseite. Tritosternum (Fig. 24) in seiner distalen Hälfte plötzlich schmäler, in der Mitte mit zwei seitlichen kleinen dreieckigen durchsichtigen Blättchen, distal mit zwei grösseren lanzettförmigen durchsichtigen Blättchen; Zipfel ziemlich breit. Jugu larschilder (Fig. 23) klein, fast Y-förmig. Sternometasternalschild gewöhnlich, mit den 3 Paar Sternal- und 1 Paar Metasternalborsten. Analschild von gewöhnlicher Grösse, vorn mehr oder weniger zugespitzt. Inguinalschilder klein, schmal. Peritrematalschilder als sehr kleine Stückchen binter den Stigmata kaum bemerkbar. Peritrema lang, vor den Schultern dorsal werdend, und das Capitulum fast erreichend. Die Haare sind alle Borsten; ungefähr 12 Paar im ventralen Teile, und ungefähr 8 marginale Paare. Bemerkenswert sind ferner 4 Haare hinter jeder Coxa IV, welche so winzig sind, dass sie in der Figur nur als Punkte angegeben sind. 
Epistom (Fig. 25) mit zwei seitlichen chitinösen Leistchen; vorn gut von den seitlichen Partien geschieden und mit einer feinen Querleiste; Vorderkante dreispitzig; Sei enspitzen scharf; Mittelspitze abgestumpft, distal selbst ein wenig konkav. Styli normal.

Mandibeln kurz: wenn ganz eingezogen, gehen sie kaum über den Vorderrand des Sternalschildes hinaus. Scheren (Fig. 26) nicht gedrungen, auch nicht schlank, mit den beiden Sinnesorganen. Oberkiefer mit 3 kleinen Schneide-, 3 oder 4 stumpfen kleinen Eck-, kleinen Backenzähnen, und mit einem Grübchen zur Aufnahme der Spitze des grossen Eckzahnes des Unterkiefers. Dieser mit 2 kleinen Schneidezähnen, einem kleiner und einem grossen Eckzahne und einem langen niedrigen, blattförmigen Backenzahne. Pulvillum: eine Reihe von Borsten.

Maxillen. Hypostom (Fig. 24) mit ungefähr 9 Querreihen von winzigen Zähnchen, von welchen die zweithinterste die längste ist; Seiten des vorderen Teiles fast gleichlaufend; an der Basis der Hörner ein Höckerchen, von dem aus ein feines Leistchen nach hinten und innen läuft; mehr nach innen wieder ein Paar Höckerchen, welche sich in den innersten Zipfeln der inneren Malae fortsetzen. Diese werden von den zwei Fächern oder äusseren Malae seiłlich begrenzt, von denen wieder der innerste Zipfel länger ist als der schon erwähnte und über diesen nach innen gebogen. Hörner normal. Palpen: dorsal (Fig. 22): Femur distal und intern mit dem kleinen durchsichtigen daumenförmigen Anhange, und proximal mit dem nach innen und vorne gebogenen Haare. Ventral (Fig. 27): Trochanter proximal und intern mit einem halbkreisförmigen platten Auswuchse, distal und intern mit einem durchsichtigen Dörnchen; Femur extern mit einer Borste, intern mit einem tiefgespaltenen Haare, dessen hinterer Ast borstenförmig, und deren vorderer Ast messerförmig ist. Genu intern mit 2 messerförmigen Haaren. Tibia und Tarsus normal.

Beine (Fig. 22) schlauk, 800 resp. 560, 560 und $850 \mu$ lang. Tarsus IV mit einem Tasthaare. Praetarsus IV (Fig. 28) mit langen nach innen gebogenen Tarsalhaaren, einer superunguinalen gerundeten Haftscheibe, welche in der Mitte kaum zugespitzt ist, und mit einer grossen gerundeten subunguinalen Haftblase.

Fundort: unter Steinen. - Type in coll. Oudemans.

9. P. consimilis Oudms et Vgts.

(Taf. XIV, Fig. $29-35$.)

P. consimilis Oudms. et Vgts.: Zool. Anz. 27, p. 652 (14. 6. 1904).

Deutonympha. Länge: $616-656 \mu$. Farbe und Textur gewöhnlich. Gestalt wie die der Deuton. des P. affinis Oudms.

Rückenseite (Fig. 29) mit zwei Schildern. Vorderschild hinten konvex. Hinterschild vorne konvex, aber in der Mitte ist dieser Rand gerade, wenn nicht sogar ein wenig konkav; hinten nicht ganz rund, sondern ziemlich zugespitzt, so dass das Schild 
ziemlich fünfeckig erscheint mit gerundeten Seiten und Ecken. Peritrematalschilder vor den Schultern sichtbar. Die Haare sind alle Borsten. Bemerkenswert sind folgende starke Borsten: die Verticalhaare, die Schulterhaare, ein Paar auf der vorderen und ein Paar auf der hinteren Hälfte des Vorderschildes, und 4 Haare im hinteren Saum des hinteren Schildes. Auch die weiche Haut um das Hinterschild trägt zwei Reihen Borsten.

Bauchseite. Tritosternum (Fig. 31) in seiner distalen Hälfte schmäler, in der Mitte mit kleinen seitlichen dreieckigen durchsichtigen Läppchen, distal mit etwas grösseren ebensolchen; die Zipfel ziemlich platt. Jugularschilder (Fig. 30) klein, niedrig-dreieckig. Sternometasternalschild gewöhnlich, breit. Analschild von gewöhnlicher Grösse, aber ein wenig eingeengt vor dem Anus, daher mehr oder weniger birnförmig. Inguinalschilder klein, schmal. Peritrematalschilder kaum sichtbar als kleine Dreiecke hinter den Stigmata. Die Haare der Bauchseite sind fast alle kräftige Borsten, ungefähr 11 Paare am ventralen Teile und ungefähr 9 marginale Paare. Bemerkenswert sind 3 winzige Härchen an der hinteren internen Seite der Coxa IV.

Epistom (Fig. 32) mit zwei seitlichen chitinösen Leistchen, mittlere Partie teilweise von den seitlichen Teilen geschieden und vorne mit einer sehr feinen Querlinie; Vorderkante dreispitzig; Seitenspitzen scharf; Mittelspitze abgestumpft, selbst ein wenig konkav. Styli gewöhnlich.

Mandibeln kurz; wenn ganz eingezogen gehen sie ein wenig üoer den Vorderrand des Sternalschildes hinaus. Scheren (Fig. 33) nicht schlank, doch ziemlich lang, mit den beiden Sinnesorganen; Oberkiefer mit 3 kleinen gleichgrossen Schneidezähnen und 4 kleinen Eckzähnen; keine Backenzähne. Unterkiefer mit einem starken Schneidezahne und 3 Eckzähnen, welche nach hinten gerichtet sind und nach hinteu an Grösse zunehmen; Backenzahn lang, niedrig, blattartig. Pulvillum: eine Reihe von Haaren.

Maxillen. Hypostom (Fig. 31) mit einer vorderen medianen breiten viereckigen Vertiefung und mit ungefähr 6 Querreihen winziger Zähnchen, von denen die hinterste und dritthinterste die längsten sind. Seiten des vorderen Teiles unduliert; Hörner normal; die inneren Malae bestehen jede aus einem inneren Zipfel und einem äusseren Fächer. Von diesem Fächer ist der innerste Zipfel länger als der schon erwähnte innere Zipfel und üher diesen nach innen gebogen. Palpen: dorsal (Fig. 29): Femur distal und intern mit dem gewöhnlichen durchsichtigen kleinen daumenförmigen Auswuchse, proximal mit dem nach innen und vorne gebogenen Haare. Ventral (Fig. 34): Trochanter proximal mit einem gerundeten platten chitinösen Anhange, distal und intern mit einem durchsichtigen Dörnchen. Femur extern mit einer Borste, intern mit einem tiefgespaltenen Haare, von dessen beiden Ästen der hintere borstenförmig, der vordere messerförmig ist. Genu intern mit zwei messerförmigen Haaren. Tibia und Tarsus normal. 
Beine (Fig. 29) schlank, 770 resp. 460, 460 und $770 \mu$ lang. Tarsus IV mit einem Tasthaare. Praetarsus IV (Fig. 35) mit kurzen Tarsalhaaren, breiter rautenförmiger superunguinaler Haftscheibe und breiter subunguinaler Haftblase.

Fundort: unter Steinen. - Type in coll. Oudemans.

10. P. congener Oudms. et Vgts.

(Taf. XIV, Fig. 36-42.)

P. congener Oudms. et Vgts.: Zool. Anz. 27, p. 652 (14. 6. 1904).

Deutonympha. Länge: 584-616 $\mu$. Farbe gewöhnlich. Gestalt wie die der Deuton. von $P$. affinis Oudms. Textur: schuppig in den harten, fein gefalten in den weichen Teilen.

Rückenseite (Fig. 36) mit zwei Schildern. Vorderschild hinten fast gerade. Hinterschild vorn konvex, so dass die beiden Sohilder einander nur in der Mitte berühren und zwei grosse dreieckige nackte weiche Teile, an jeder Seite einen, zwischen sich lassen. Vor den Schultern sind die vorderen Teile der Peritrematalschilder sichtbar. Alle Haare sind Borsten. Bemerkenswert sind die zwei Verticalhaare, die Schulterhaare, ein Paar auf der Vorderhälfte und ein Paar auf der Hinterhälfte des Vorderschildes, und zwei Paar in dem hinteren Saume des hinteren Schildes. Auch die weiche Haut um das Hinterschild trägt zwei Reihen Borsten.

Bauchseite. Tritosternum (Fig. 38) kurz, in der distalen Hälfte plötzlich schmäler, in der Mitte mit zwei seitlichen dreieckigen durchsichtigen Läppchen, und distal mit zwei grösseren ebensolchen Läppchen. Zipfel ziemlich breit. Jugularschilder (Fig. 37) klein, Y-förmig. Sternometasternalschild gewöhnlich. Analschild gewöhnlich. Inguinalschilder klein, schmal, vorn zugespitzt. Peritrematalschilder unbemerkbar (auf der Bauchseite; auf der Rückenseite siehe oben). Ha are borstenförmig. Bemerkenswert sind zwei Paar Haare hinter Coxae IV, welche ihrer Kleinheit wegen in der Figur nur als Punkte angegeben sind.

Epistom (Fig. 39) seitlich mit zwei chitinösen Leistchen; Zentralteil wohl begrenzt von den Seitenteilen; Mittelteil vorne mit zwei queren Leistchen; Vorderkante dreispitzig; Spitze von normaler Grösse; Seitenspitzen scharf, Mittelspitze-abgestutzt, kaum konkav. Styli ziemlich lang.

Mandibeln ziemlich kurz; wenn ganz eingezogen, gehen sie an dem Vorderrande des Sternalschildes vorbei. Scheren (Fig. 40) ziemlich kräftig, mit den beiden Sinnesorganen; Oberkiefer mit 3 gleichgrossen Schneidezähnen, 2 kleinen stumpfen Eckzähnen, einem gerundeten grösseren Eckzahne, und einem langen blattartigen Backenzahne. Unterkiefer mit einem grossen und 2 kleineren Schneidezähnen, einem starken nach hinten gerichteten Eckzahne und einem hohen blattartigen Backenzahne, welcher mit dem des Oberkiefers eine Schere bildet. Pulvillum: eine Reihe von Haaren. 
Maxillen. Hypostom (Fig. 38). Die Mittelpartie ist von den Seitenpartien durch ein unduliertes Leistchen wohl geschieden und mit ungefähr 9 queren Reihen von winzigen Zähnchen versehen, von welchen die hinterste wie ein $\wedge$ mit weit ausgebreiteten Ästen geformt ist. Zwischen den Haaren I und II ein hantelförmiges Grübchen. Hörner normal; innere Malae zwei gefranste Fächer darstellend, deren Gipfel ungefähr in einer Querreihe liegen, und deren innerste Zipfel breiter sind als die übrigen. Palpen: dorsal (Fig. 36): Femur mit dem nach innen und vorne gebogenen Haare, und distal und intern mit dem kleinen daumenförmigen Auswuchse. Ventral (Fig. 41): Trochanter proximal mit einem platten gerundeten chitinösen Auswuchse, distal und intern mit einem Dörnchen. Femur extern mit der gewöhnlichen Borste, intern mit einem tiefgespaltenen Haare, von dessen Ästen der hintere borstenförmig und der vordere messerförmig ist. Genu intern mit 2 messerförmigen Haaren. Tibia und Tarsus normal.

Beine (Fig. 36) schlank, 710 resp. 495, 495 und $745 \mu$ lang. Tarsus IV mit Tasthaaren. Praetarsus IV (Fig. 42) mit kurzen Tarsalhaaren, welche kaum die subunguinale Haftblase erreichen, mit vierlappiger superunguinaler Haftscheibe, von deren Läppchen die zwei inneren viel grösser sind als die äusseren, und mit grosser zweilappiger subunguinaler Haftblase.

Fundort: unter Steinen. - Type in coll. Oudemans.

\section{P. beta Oudms. et Vgts.}

(Taf. XV, Fig. $43-51$.)

P. beta Oudms. et Vgts: Zool. Anz. 27, p. 652 (14.6. 1904).

Deutonympha. Länge: $560 \mu$. F a rbe gewöhnlich. Gestalt wie die der Deuton. des P. affinis Oudms. Textur: schuppig in den harten, fein gefaltet in den weichen Teilen.

Rückenseite (Fig. 43) mit zwei Schildern. Vorderschild hinten ein wenig konvex; Hinterschild vorn ein wenig konvex, so dass die Schilder sich nur in ihrer Mitte berühren. Vor den Schultern sind die vorderen Teile der Peritrematalschilder sichtbar. Haare in der gewöhnlichen Zahl und Stellung. Bemerkenswert sind die Verticalhaare, die Schulterhaare, ein Paar auf der vorderen und ein Paar auf der hinteren Hälfte des Vorderschildes, und 4 Haare im hinteren Saume des Hinterschildes; diese Haare sind kräftige Borsten. Auch in der weichen Haut um das Hinterschild sind eine oder zwei Reihen kurzer Borsten.

Bauchseite. Tritosternum (Fig. 45) kurz, in der distalen Hälfte plötzlich schmäler, nur distal mit seitlichen durchsichtigen lang-dreieckigen Läppchen versehen, ausser den beiden ziemlich b reiten Zipfeln. Jugularschilder (Fig. 44) klein, Y-förmig. Sternometasternalschild normal. Analschild von gewöhnlicher Grösse, vor dem Anus etwas eingeengt, birnförmig. Inguinalschilder klein, länglich-oval. Peritrematalschilder nur durch 
einen seitlichen schmalen Streifen vor den Schultern dargestellt. Alle Haare der Bauchseite sind Borsten, und zwar 11 Paar im ventralen Teile und ungefähr 7 Paar im Saumteil. Bemerkenswert sind 2 Paar winzig kleine Haare hinter den Coxae IV und 1 Paar sehr kleine zwischen den Inguinal- und Analschildern, ferner 1 Paar seitlich vom Analschild, welche kräftiger sind.

Epistom (Fig. 46) dreispitzig; Spitzen ziemlich lang; Mittelspitze länger, distal mit 3 winzigen Spitzchen. Styli normal. An den Seiten zwei chitinöse Leistchen; der mittlere Raum deutlich begrenzt von dem seitlichen (den Coxae der Palpen).

Mandibeln kurz; wenn ganz eingezogen, erreichen sie das Sternalschild. Tibiotarsus ungewöhnlich aufgeblasen (Fig. 47 ist eine Rücken-, Fig. 48 eine Seitenansicht). Scheren (Fig. 49) ziemlich klein, mit Sinnesorganen; Oberkiefer mit zwei kleinen Schneidezähnen, zwei kleinen Eckzähnen und einem eckzahnförmigen platten Backenzahne; Unterkiefer mit zwei Schneidezähnen, von denen der vordere der grössere ist, zwei Eckzähnen, von denen der hintere der grössere und nach hinten gerichtet ist, und einem langen, niedrigen, platten Backenzahne, welcher mit dem des Oberkiefers eine Schere bildet.

Maxillen. Hypostom (Fig. 45) mit den gewöhnlichen 4 Paar Haaren, mit ungefähr 8 Querreihen winziger Zähnchen und mit zwei longitudinalen Leisten im mittleren Raum der Vorderhälfte, diese mit ein wenig nach vorne convergierenden Kanten; Hörner klein; die inneren Malae sind gefranste Fächer, von deren Zipfeln die innersten die längsten sind. Palpen: dorsal: Femur proximal mit einem nach innen und vorne gebogenen Haare, distal und intern mit einem durchsichtigen daumenähnlichen Fortsatze, welcher nach vorn gerichtet ist. Ventral (Fig. 50): Trochanter mit den beiden gewöhnlichen Borsten, proximal mit einem ovalen chitinösen Höcker, distal und intern mit einem kleinen durchsichtigen Dörnchen. Femur extern mit einer Borste, intern mit einem gespaltenen Haare, deren hintere Hälfte borstenförmig und deren vordere Hälfte messerförmig ist. Genu intern mit den zwei messerförmigen Haaren.

Beine (Fig. 43) schlank, 675 resp. 400, 400 und $610 \mu$ lang. Tarsus IV mit Tasthaaren. Praetarsus IV (Fig. 51) mit 2 Tarsalhaaren, welche kaum die Klauen erreichen, einer grossen superunguinalen vierlappigen Haftscheibe und einer grossen kugelförmigen subunguinalen Haftblase.

Fundort: unter Steinen. - Type in coll. Oudemans.

12. P. alpha Oudms, et Vgts.

(Taf. XV, Fig. 52-58.)

P. alpha Oudms. et Vgts.: Zool. Anz. 27, p. 653 (14. 6. 1904).

Deutonympha. Länge: $464-488 \mu$. Farbe strohgelb. Gestalt wie die der Deuton. des $P$. affinis Oudms. Textur: geschuppt in den harten, fein gefaltet in den weichen Teilen. 
Rückenseite (Fig. 52) mit zwei Schildern, 280 resp. $200 \mu$ lang. Vorderschild hinten gerade, Hinterschild vorne ebenso; eine weiche Haut zwischen den Schildern war nicht sichtbar. Beide Schilder mit kurzen Borsten versehen, in gewöhnlicher Zahl und Stellung. Bemerkenswert sind nur 2 winzige Haare in der Mitte des Vorderschildes und die Schulterhaare, welche ungefähr so lang sind als die Hälfte der Körperbreite.

Bauchseite. Tritosternum (Fig. 54) kurz, distale Hälfte plötzlich schmäler; distal mit einem kleinen dünnen gefransten Läppchen an jeder Seite und mit den gewöhnlichen gefiederten Verlängerungen. Sternometasternalschild (Fig. 53) vorn breit, nach hinten laugsam sich verschmälernd. Bemerkenswert ist die grosse Entfernung zwischen dem ersten und zweiten Paare der Sternalhaare. Analschild von gewöhnlicher Grösse, rund, mit dem gewöhnlichen circumanalen Haare und dem Cribrum. Inguinalschilder klein, undeutlich. Haare am Bauche klein, ungefähr 8 Paare; im hinteren Leibessaume 3 Paar. Stigmata in einer Linie ein wenig vor der Mitte der Foveolae pedales IV. Peritremata lang, hinter den Beinen II dorsal werdend. Peritrematalschilder deutlich, besonders innerseits von Peritrema und hinter dem Stigma, wo sie in ein kleines Dreieck verlängert sind.

Epistom (Fig. 55) dreispitzig; die drei Spitzen gleichlang und scharf, die äusseren ein wenig divergierend. Styli verhältnismässig lang.

Mandibeln kurz; wenn ganz eingezogen, das Sternalschild erreichend. Scheren (Fig. 56) ziemlich schlank; Oberkiefer mit 2 Schneide- und 3 Eckzähnen, diese sind etwas nach vorne gerichtet. Die beiden Sinnesorgane sind vorhanden. Unterkiefer mit einem Schneide- und 3 Eckzähnen, alle nach hinten gerichtet und gleichlang. Pulvillum: eine Reihe von Haaren.

Maxillen. Hypostom (Fig. 54) ziemlich kurz, viereckig, mit den gewöhnlichen 4 Paar Haaren. Hörner, innere Malae und Franse gewöhnlich. In der Nähe der Basis der Hörner ein kleiner Höcker, nach innen gerichtet, ein kleines Horn nachahmend. Palpen: dorsal (Fig. 52): Femur distal und intern mit dem durchsichtigen Däumling, proximal und median mit dem nach innen und vorne gebogenen Haare. Ventral (Fig. 57): Trochanter mit mit 2 Borsten; Femur intern mit einem tiefgespaltenen glatten Haare, extern mit einer Borste; Genu intern mit 2 messerförmigen Haaren; Tibia und Tarsus normal.

Beine (Fig. 52) 425 resp. 265, 290 und $475 \mu$ lang; schlank. Tarsus IV mit langem Tasthaare. Praetarsus IV (Fig. 58) kurz, mit langen Tarsalhaaren, nur einem superunguinalen zweilappigen Haftscheibchen und einer subunguinalen zweilappigen Haftblase.

Fundort: unter Steinen. - Type in coll. Oudemans. 
13. P. theta Oudms. et Vgts.

(Taf. XV, Fig. 59-62; Taf. XVI, Fig. 63-65.)

P. theta Oudms. et Vgts.: Zool. Anz. 27, p. 653 (14. 6. 1904).

Larva. Länge: $440 \mu$. Farbe: weiss. Gestalt dick, oval, kaum geschultert. Textur: glatt.

Rückenseite (Fig. 59) mit 9 Paar kleiner und nur 1 Paar starker Borsten; letztere hinter der Ansatzstelle des III. Beinpaares.

Bauchseite. Tritosternum (Fig. 61) sehr lang; in seiner distalen Hälfte seitlich ein wenig behaart; distal mit 3 Ästen, deren mittlerer eine Verlängerung des Stammes ist. Dieser Ast distal gegabelt, und seine Ästchen ein wenig gefiedert. Die Borsten der Bauchseite (Fig. 60) an den gewöhnlichen Stellen.

Ep istom (Fig. 62) dreispitzig, Mittelspitze klein, dreieckig; Seitenspitzen divergierend, scharf. Styli kurz und dick.

Mandibeln kurz; wenn ganz eingezogen, erreichen sie das erste Paar der Sternalhaare. Scheren (Fig. 63) stark, mit Sinnesorganen. Oberkiefer mit 3 Schneidezähnen, 2 scharfen dreieckigen Eckzähnen und einem Einschnitt im übrigbleibenden Teile des Kiefers, nicht weit vom hintersten Eckzahne entferut. Unterkiefer mit einem grossen Schneidezahn und 3 scharfen Eckzähnen, welche ein wenig nach hinten gerichtet sind, und deren mittlerer der grössere ist. Pulvillum: eine Reihe von Borsten.

Maxillen. Hypostom (Fig. 61) mit nur 2 Paar Haaren; Hörner normal; innere Malae nur von einem halbkreisförmigen Läppchen mit langer Franse gebildet; die drei oder zwei innersten Zipfel dieser Franse kreuzen einander. Palpen (Fig. 64) ventral: Trochanter nackt; Femur extern mit einer Borste, intern mit einem gestielten messerförmigen Haare; Genu intern mit falzbeinförmigem Haare: Tibia und Tarsus normal.

Beine nicht schlank, auch nicht ziemlich dick; 480 resp. 260 und $300 \mu$ lang. Praetarsus IV (Fig. 65) kurz; die Tarsalhaare gehen über die Klauen hinaus; Distalhaare kräftig; Klauen stark; superunguinales Haftscheibchen oval, distal in einen Zipfel verlängert; subunguinale Haftblase kugelförmig.

Fundort: unter Steinen. - Type in coll. Oudemans.

14. P. zeta Oudms. et Vgts.

(Taf. XVI, Fig. $66-72$.)

P. zeta Oudms. et Vgts.: Zool. Anz. 27, p. 653 (14. 6. 1904).

Larva. Länge: $320-336 \mu$. Farbe: weiss. Gestalt wie die der Larve des $P$. coleoptratorum (L). Textur: weder Schildchen noch Hautfältchen waren bemerkbar, so dass die Haut glatt genannt werden kann.

Rückenseite (Fig. 66). Auf ungefähr zwei Drittel der Körperlänge zeigt der Rücken eine Querfalte, welche wohl als Grenze anzusehen ist, zwischen dem arachnoidischen Prosoma und Metasoma. Auf dem Prosoma bemerken wir 1 Paar Verticalhaare, 1 Paar starke 
Borsten in einer Linie mit den Beinen II, 1 noch stärkeres Paar in einer Linie mit den Beinen III und 6 Paar kleinerer Borsten. Es ist deutlich, dass wir es hier mit einer Andeutung von zu drei Segmenten gehörenden starken Borstenpaaren zu tun haben. Auf dem Metasoma 7 Paare kleiner Borsten.

Bauchseite. Tritosternum (Fig. 68) lang; in seinem distalen Dritteil kaum gefranst; distal gegabelt, die beiden Äste nochmals gegabelt; zwischen den beiden Ästen erster Ordnung ein kleines Läppchen; die 4 Zipfel sind gefiedert. Sekundärschilder sind nicht vorhanden. Borsten (Fig. 67): 1 Paar auf einer Linie zwischen Coxae I und II, 1 Paar zwischen Coxae II, 1 Paar zwischen Coxae III, 3 Paar in der vorderen und 2 Paar in der hinteren Hälfte des Bauches; endlich die gewöhnlichen Circumanalhaare, von denen die seitlichen starke Borsten sind und das postanale eine $210 \mu$ lange Borste.

Epistom (Fig. 69) dreispitzig; die Mittelspitze kurz und gerundet; die Seitenspitzen lang, divergierend, scharfspitzig. Styli normal. Keine Zeichnungen.

Mandibeln kurz; wenn sie ganz eingezogen sind, erreichen sie das erste Paar der Sternalborsten. Scheren (Fig. 70) mit basalem und dentalem Sinnesorgane; Oberkiefer mit 5 Unterkiefer mit 4 Zähnen; die des Oberkiefers scheinen etwas vorwärts, die des Unterkiefers etwas nach hinten gerichtet.

Maxillen. Hypostom (Fig. 68) mit nur 2 Paar Haaren versehen und mit einem Paar dreieckiger Höckerchen, wo gewöhnlich das vierte Paar steht. Hörner klein. Innere Malae sehr grosse, durchsichtige, schön gefranste Blätter. Palpen: dorsal (Fig. 66): Femur ohne das distale interne Dörnchen und ohne das zentrale nach innen und vorne gebogene Haar. Ventral (Fig. 71): Trochanter nackt; Femur intern mit messerförmigem Haare, welches an seiner Basis kaum gegabelt, an seinem Ende fein gezähnelt ist; Genu mit nur einem Messer, welches an seinem Ende fein gezähnelt ist. Tibia mit den gewöhnlichen 2 distalen Haaren, von welchen jedoch das äussere sehr lang und haarförmig ist. Tarsus normal.

Beine 500 resp. 280 und $330 \mu$ lang; ziemlich dick. Femur I dorsal (Fig. 66) und intern mit einem dreieckigen Höckerchen. Femur III ventral (Fig. 67) mit einem kurzen breiten Dörnchen. Praetarsus III (Fig. 72) mit langen Tarsalhaaren, einem Paar Distalhaare, einem Paar von breit-lanzettförmigen superunguinalen Haftscheibchen, welche distal in ein Haar ausgezogen sind, und mit einem subunguinalen Haftbläschen.

Fundort: unter Steinen. - Type in coll. Oudemans.

Diese Art wurde auch von Dr. Heim in Hutpilzen bei Buré (Frankreich) gefunden. 
15. P. setosus Oudms, et Vgts.

(Taf. XVI, Fig. 73-79.)

P. setosus Oudms. et Vgts.: Zool. Anz. 27, p. 653 (14. 6. 1904). Deutonympha. L,änge: 720-944 $\mu$. Farbe: gewöhnlich. Gestalt breit, ungewöhnlich bei Parasitus. Textur gewöhnlich.

Rückenseite (Fig. 73) von zwei Schildern gedeckt, welche 380 resp. $300 \mu$ lang sind. Das hintere Schild fast dreieckig, m,t runden Seiten und runden Ecken. Alle Haare sind fein, glatt und verhältnismässig lang; doch sind die gewöhnlichen längeren Haare, $6 \mathrm{im}$ vorderen Schilde und 2 am Hinterrande des hinteren Schildes, deutlich. Zwei oder vier Verticalhaare sind nach vorne gerichtet. Bei und etwas hinter den Schultern ein borstenförmiges Haar, wenigstens doppelt so lang als die anderen Haare und ein wenig nach aussen gerichtet. Etwas hinter diesem langen Haare und gerade am Leibesrande, also in der weichen Haut, eine steife Borste, auswärts und ein wenig vorwärts gerichtet, also ein Schulterhaar nachahmend. Zwei Reihen von Haaren in der weichen Haut, welche das hintere Schild umgibt.

Bauchseite. Tritosternum (Fig. 75) gewöhnlich; jedoch besitzt es distal, ausser den gewöhnlichen fiederförmigen Verlängerungen, ein Paar kurze, durchsichtige, gefranste, dünne Blättchen. Jugula rschilder (Fig. 74) gewöhnlich. Sternometasternalschild mit den gewöhnlichen 4 Paar Haaren. Analschild klein, oval, Spitze nach hinten, mit den gewöhnlichen 3 kleinen Haaren und dem Cribrum. Peritrematalschilder nur repräsentiert von einem kommaförmigen sehr kleinen Stückchen hinter dem Stigma und einem schmalen Streifen an der Aussenseite des Peritrema bei Coxae II. Inguinalschilder klein, dreieckig. Zwischen Coxae IV ein Paar Haare; hinter Coxae IV ein Paar ausserordentlich kleiner Haare; am Bauche die gewöhnliche Anzahl Haare. Alle Haare an der Bauchseite des Körpers sind fein und glatt.

Epistom (Fig. 76) dreispitzig, aber die Seitenspitzen tragen an ihrer Aussenseite eine kleinere Spitze, so dass das Epistoma ein Übergang von einem drei- zu einem fünfspitzigen genannt werden kann. An den Seiten des Epistoma die langen Styli.

Mandibeln kurz; wenn sie ganz eingezogen sind, erstrecken sie sich bis zum Sternometasternalschilde. Scheren (Fig. 77) kurz, stark, vielzähnig. Oberkiefer (distale Hälfte des Tibiotarsus) mit 3 Schneidezähnen und 3 Eckzähnen; keine Backenzähne. Zwischen den Schneide- und Eckzähnen ein Sinnesorgan. An der Rückenseite, über der Ansatzsteile des Unterkiefers ebenfalls ein Sinnesorgan. Pulvillum: eine Reihe von etwa 12 divergierenden Haaren. Vor dem erstgenannten Sinnesorgane, an der Seite des Oberkiefers, ein kleiner viereckiger Auswuchs, gegen dessen Vorderseite die Innenseite des Schneidezahnes des Unterkiefers ruht, wenn die Schere geschlossen ist. Unterkiefer (Telotarsus) mit einem Schneide- und 3 Eckzähnen; keine Backenzähne, ausser einem dünnen Blättchen. 
Maxillen. Hypostom (Fig. 75) fast viereckig; Hörner kurz und breit; innere Malae nur von zwei Zipfeln gebildet, welche an ihrer Aussenseite und in ihrer proximalen Hälfte gefranst sind. Palpen: dorsal (Fig. 73): Femur distal und intern mit einem durchsichtigen kleinen Dörnchen. Ventral (Fig. 78): Trochauter mit den gewöhnlichen 2 Haaren, von welchen das distale in seiner Mitte plötzlich ein wenig gebogen ist; proximal mit einem chitinisierten, blattförmigen Anhange; distal und intern mit einem durchsichtigen Dörnchen; Femur intern mit einem tiefgespaltenen, durchsichtigen Haare, an dessen Basis sich ein unregelmässiges mattes Fleckchen befindet; Genu intern mit 2 durchsichtigen messerförmigen Haaren, die Schneide dieser Messer nach vorne; Tarsus mit dem gewöhnlichen dreigabeligen Haare.

Beine 855 resp. 665,570 und $850 \mu$ lang, schlank. Bein II doppelt so dick als die anderen Beine. Alle Femora mit Basifemur. Tarsi II, III und IV mit Basitarsus und scharfspitzigen Borsten, ganz besonders Tarsus IV, der auch mit einem langen Fühlhaare versehen ist. Femur III und IV und Trochanter IV distal und dorsal mit einem dornförmigen Haare. Praetarsus IV (Fig. 79) kurz, mit langen Tarsalhaaren, grosser vierlappiger superunguinaler Haftscheibe und grosser quer-ovaler subunguinaler Haftblase.

Fundort: hinter der Anstaltsmauer, unter feuchten Steinen (1 Deut.) 1. 9. 01. - Type in coll. Oudemans.

16. P. consors Oudms. et Vgts.

(Taf. XVII, Fig. 80-86.)

P. consors Oudms. et Vgts.: Zool. Anz. 27, p. 654 (14. 6. 1904).

Deutonympha. Länge: $616 \mu$. Farbe: die gewöhnliche der Parasitiden. Gestalt wie die der Deutonympha des P. affinis Oudms. Textur: schuppig in den harten, fein gefaltet in den weichen Teilen.

Rückenseite (Fig. 80) von zwei Schildern gedeckt. Vorderschild hinten gerade; Hinterschild vorne ein wenig konvex; die mittlere Partie dieses Vorderrandes unduliert. Haare ziemlich lang, glatt, fein; die des Hinterschildes etwas länger als die des Vorderschildes. Zwei Vertikalhaare nach vorne gerichtet. Zwei Schulterhaare und vier Haare im hinteren Saume des Hinterschildes sind mindestens doppelt so lang als die übrigen Haare. Hinter den Schulterhaaren steht eine kleine Borste senkrecht auf der Leibeskante, und zwar in der weichen. Haut.

Bauchseite. Tritosternum (Fig. 82) lang, proximal ein wenig breiter, ebenso distal, wo sich eine schmale kaum merkbare Franse befindet; die beiden Zipfel normal. Jugularschilder (Fig. 81) gross. Sternometasternalschild merkbar verschmälert zwischen den Coxae II; das vorderste Paar der Sternalhaare ist in einem weniger chitinisierten queren Rande eingepflanzt. Analschild normal. Inguinalschilder klein, rund. Peritrematalschilder 
sehr schmal, ganz eingenommen von dem Peritremata, daher unsichtbar, wenigstens im ventralen Teile. Haare ungefähr 18 Paare im ventralen Teile, von denen 2 Paare hinter Coxae IV und 1 Paar zwischen den Inguinal- und Analschildern so winzig sind, dass sie in der Zeichnung nur durch Punkte angedeutet sind.

Epistom (Fig. 83) dreispitzig; Spitzen kurz; mittlere Spitze abgestutzt; Seitenspitzen scharf und ein wenig divergierend. Kanten des Capitulums unduliert, mit einer kleinen chitinösen Leiste in der Mitte. Styli normal.

Mandibeln kurz; wenn ganz eingezogen, kaum an der Vorderkante des Sternalschildes vorbeigehend. Scheren (Fig. 84) kräftig, mit Sinnesorganen; Oberk i efer mit 2 gleichgrossen Schneidezähnen, 3 stumpfen Eckzähnen, von denen der dritte der längste ist und 1 niedrigen blattartigen Backenzahn ganz hinten. Unterkiefer mit 3 Schneidezähnen, von denen der vorderste mindestens zweimal kräftiger ist, 1 breiten nach hinten gerichteten Eckzahn und 1 hohen blattartigen langen Backenzahn, welcher mit dem des Oberkiefers eine Schere bildet (wie eine Schere wirkt). Pulvillum: eine Reihe von Haaren.

Maxillen. Hypostom (Fig. 82) schön, mit undalierten Seiten, schönen Zeichnungen um die Haare III, brillenförmigen Zeichnungen um die Haare I, geraden und langen Zipfeln der inneren Malae und steifer Franse. Palpen: dorsal (Fig. 80): Femur distal und intern mit einem kleinen durchsichtigen daumenförmigen Anhange, in der Mitte und intern mit einem nach innen und vorne gerichteten Haare. Ventral (Fig. 85): Trochanter mit den gewöhnlichen Borsten, die proximale nach aussen gerichtet, die distale nach innen; Femur extern mit der gewöhnlichen Borste, intern mit dem messerförmigen Haar, welches einen gesägten Rücken hat; Genu intern mit 2 messerförmigen Haaren; Tibia und Tarsus normal.

Beine (Fig. 80) 575 resp. 365, 415 und $575 \mu$ lang, schlank. Tarsus IV mit langem Tasthaare. Praetarsus IV (Fig. 86) mit einer grossen vierlappigen superunguinalen Haftscheibe, einer grossen kugelförmigen subunguinalen Haftblase und 2 langen Tarsalhaaren.

Fundort: unter Steinen. - Type in coll. Oudemans.

\section{Pergamasus Berl.}

17. P. Iongulus (Oudms.) 1902 (syn. runcatellus Berl. 1903).

Unter Ziegelsteinen: bei der Mühle $\left(\begin{array}{ll}1 & \delta^{\top}\end{array}\right)$ 4. 9. 01. - In Moos: Hausgarten (1 ㅇ) 20.4.01.

\section{P. crassipes (L.).}

Unter feuchten Steinen: bei der Brücke über die „alte“ Weser

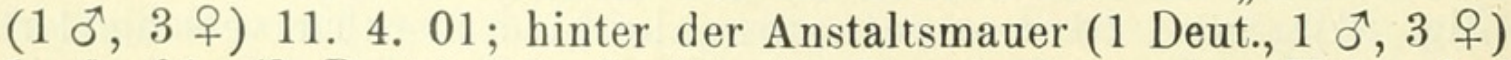
1. 9. 01, (3 Deut.) 15. 9. 01, (1 Deut.) 9. 4. 02; Hühnerhof (2 Deut.) 9. 9. 01. - Unter faulendem Holz: hinter Finkenau (1 오) 24. 8. 01. 


\section{P. septentrionalis (Oudms.).}

Unter Ziegelsteinen: Hühnerhof 1 o, 1 ㅇ) 9. 9. 01; hinter der Anstaltsmauer (1 $\sigma^{\top}, 2$ 우) 15. 9. 01.

\section{P. canestrinii (Berl.).}

Hühnerhof, unter Holz (1 Lv.) 15. 9. 01.

\section{P. gamma Oudms, et Vgts.}

(Taf. XVII, Fig. 87-94.)

\section{F. gamma Oudms. et Vgts.: Zool. Anz. 27, p. 654 (14.6. 1904),}

Protonympha. Länge: $720 \mu$. Farbe bleich. Gestalt wie die der Protonympha des $P$. crassipes (L.). Textur: geschuppt auf den Schildern, fein gefaltet in den weichen Teilen.

Rückenseite (Fig. 87) mit zwei Schildern, 400 resp. $220 \mu$. lang; jedes mit 15 Paaren kurzer Haare, so dass das Hinterschild, da es um die Hälfte kleiner ist, viel stärker behaart scheint.

Bauchseite. Tritosternum (Fig. 89) lang, distal gegabelt; die beiden Äste der Gabel lang gebärtet; die erste (proximale) Barte kräftig, Äste nachahmend, so dass scheinbar 4 Äste vom distalen Ende divergieren, zwei kleinere und zwei längere. Etwas hinter dem distalen Ende, seitlich, einige Zähnchen. Sternalschild (Fig. 88) fast überall gleichbreit, hinten gerundet; mit den gewöhnlichen 3 Paar Haaren. Analschild klein, oval, mit den gewöhnlichen 3 kleinen Circumanalhaaren. Stigmata in einer Linie mit der Mitte der Coxae IV. Peritremata klein, gebogen, auswärts konvex. Haare: zwischen Coxae IV 1 Paar, am Bauche 3 Paar, seitlich vom Analschilde 1 Paar.

Epistom (Fig. 90) vielspitzig, die mittelste und die beiden äussersten Spitzen etwas länger als die übrigen. Styli lang

Mandibeln kurz; wenn ganz eingezogen, erreichen sie das Sternalschild. Scheren (Fig. 91) mit den beiden Sinnesorganen. Oberkiefer mit einem kleinen Schueidezahn in der Nähe des Sinnesorgans, 2 kleinen Eckzähnen hinter diesem und einem Einschnitt in der Mitte des übrigen Teiles. Unterkiefer mit 4 ungefähr gleichgrossen Eckzähnen. Pulvillum: eine Reihe steifer Borsten.

Maxillen. Hypostom (Fig. 89) mit 4 Paar Haaren und median mit 14 Querreihen vou winzigen dreieckigen nach vorne gerichteten Zähnchen, von denen die vorderste Reihe ein $\wedge$ bildet und die beiden hintersten länger sind als die übrigen Reihen. Hörner gewöhnlich. Die inneren Malae bestehen aus 2 internen längeren Zipfeln, 2 externen Fächern und 2 basalen Zipfeln. Palpen: dorsal: (Fig. 87): Femur distal und intern mit einem dreieckigen durchsichtigen Auswuchse. Ventral (Fig. 92): Trochanter mit einem zentralen Haare und distal und intern mit einem durchsichtigen sehr kleinen Dorne; Femur proximal und extern mit einem Haare und intern mit einem gebogenen messerförmigen Haare, welches am Rücken gesägt ist; Geuu intern mit einem ebenso geformten Haare; Tibia und Tarsus normal. 
Beine lang, schlank, 1080 resp. 680, 640 und $880 \mu$ lang. Praetarsus IV (Fig. 93 und 94) kurz, mit langen Tarsalhaaren, den gewöhnlichen Distalhaaren, runden superunguinalen Haftscheibchen und sackförmiger subunguinaler Haftblase.

Fundort: unter Steinen. - Type in coll. Oudemans.

\section{P. bomborum (Oudms.).}

Hausgarten, auf Bombus spec. (30 Deut.) 11. 4. 02.

Bremen: auf Bombus terrestris, hortorum, Psithyrus vestalis. IV. A.

Trachygamasus Berl.

23. T. pusillus (Berl.).

Unter Ziegelsteinen: Hühnerhof (4 Deut.) 23. 8. 01, (14 Deut. 10 우) 9. 9. 01; hinter der Anstaltsmauer (2 ㅇ) 1. 9. 01, (16 \&) 15. 9. 01. Oberneuland: Jürgens Holz, unter auf der Erde liegender trockener Baumrinde (1 f) 4. 10. 01.

Gamasoides Berl.

$\dagger$ 24. G. subterraneus (J. Müll.).

Vegesack: auf Necrophorus vespillo, humator. X. P.

$\dagger$ 25. G. fucorum (Deg.).

Bremen: auf Carabus monilis (1) 27. 8. 99, cancellatus (11) 11. 9. 99, Necrophorus vespillo, (47) 11. 7.00. A. --

Vegesack: auf Necrophorus vespillo, humator. X. P.

Eugamasus Berl.

$\dagger$ 26. E. cornutus (G. et R. Can.).

Vegesack: Nest von Talpa europaea. III. P.

27. E. epsilon Oudms. et Vgts.

(Taf. XVIII, Fig. 95-103.)

E. epsilon Oudms. et Vgts.: Zool. Anz. 27, p. 654 (14. 6. 1904).

Protonym pha. Länge: $440-480 \mu$. Farbe bleich. Gestalt länglich-oval, mit fast gleichrunden Enden. Textur: geschuppt auf den Schildern, fein gefaltet in den weichen Teilen.

Rückenseite (Fig. 95) mit zwei Schildern, ungefähr 305 resp. $135 \mu$ lang. Vorderschild hinten konvex, Hinterschild vorne konkav. Vorderschild mit 3 Paar starker und 7 Paar sehr kleiner Borsten. Hinterschild mit 4 starken hinteren Borsten und 9 Paar sehr kleiner Borsten. Die Schulterborsten ein wenig nach vorne gebogen, je ein Paar starker Borsten auf der vorderen und hinteren Hälfte des Vorderschildes. Die starken Borsten sind in ihrer distalen Hälfte behaart (Fig. 101).

Bauchseite. Tritosternum (Fig. 97) normal, piedestalförmig, distal und seitlich von den fiederförmigen Verlängerungen kurz-gefranst. Sternalschild (Fig. 96) breit, mit den gewöhnlichen 
3 Paar Haaren, hinten gerundet. Analschild normal. Haare: zwischen Coxae IV ein Paar, vor dem Analschilde 3 Paar, ein Paar seitlich vom Analschilde. Stigma in einer Linie mit der Mitte der Coxae IV. Peritremata klein, nach aussen gebogen, die Foveolae pedales III nicht erreichend.

Epistom dreispitzig (Fig. 98), sehr an das der ${ }_{\mathrm{a}}^{\text {P Protonympha }}$ des Eugamasus cornutus (G. et R. Can.) erinnernd. Mittelspitze abgestutzt; Seitenspitzen nach innen gebogen, extern gezähnelt. Styli lang.

Mandibeln kurz; wenn ganz eingezogen, das Sternalschild erreichend. Scheren (Fig. 99) mit den Sinnesorganen. Oberkiefer mit 2 Schneide-, 2 Eck- und 2 Backenzähnen, alle fast von gleicher Grösse. Unterkiefer mit 3 Schneidezähnen und einem Eckzahn. Pulvillum: eine Reihe von Borsten.

Maxillen. Hypostom (Fig. 97) lang, mit 4 Paar Haaren. Innere Malae mit reicher Franse ihrer ganzen Länge nach, also fast mähnenartig. Hörner normal (Fig. 100).

Palpen: dorsal (Fig. 95): Femur distal und intern mit kleinem, nach innen und vorne gebogenen Dörnchen; proximal mit einem nach innen und vorne gebogenen Haar. Ventral (Fig. 102): Trochanter distal und intern mit einem gegabelten Haare; ein Ast desselben ist scharf, der andere platt; Genu in der Mitte und intern mit einem platten Haare; Tibia distal mit 2 Borsten; Tarsus normal.

Beine 600 resp. 450,450 und $650 \mu$, nicht sehr schlank. Tarsus IV mit langer Tastborste. Praetarsus IV kurz (Fig. 103), mit kurzen Tarsalborsten, normalen Distalhaaren und dreieckigen subunguinalen Haftscheibchen; keine subunguinale Haftblase.

Fundort: unter Steinen. - Type in coll. Oudemans.

\section{E. oudemansi Berl.}

Unter Steinen im Hühnerhof (1 Deut.) 16. 9. 02.

Vegesack: auf Talpa europaea und in dessen Nest. III. P.

Euryparasitus Oudms.

+29 . E. terribilis (Mich.).

Vegesack: Nest von Talpa europaea. III. P.

Macrocheles Latr.

30. M. subbadius (Berl.).

Hausgarten, auf Aphodius arenarius (2 ㅇ) 11. 9. 01.

31. M. badius (€. L. Koch).

Unter Steinen: hinter der Anstaltsmauer (1 우) 1. 9. 01; Weserdeich (1) 8. 9. 01. Unter auf der Erde liegendem Holz:

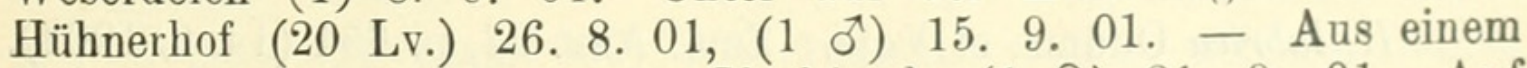
Unkrauthaufen gesiebt, vorm Blocklande (1 ㅇ) 21. 9. 01. Auf Aphodius fimetarius, Blockland (4 Deut.) 13. 4. 02. 


\section{M. merdarius (Berl.).}

Unter feuchten Steinen, hinter der Anstaltsmauer $\left(\begin{array}{ll}1 & \sigma^{\top}\end{array}\right)$ 15. 9. 01 .

\section{M. marginatus (Herm.).}

Unter Holz im Hühnerhof (8 우) 26. 8. 01, (1 우) 15. 9. 01. Bremen: auf Musca domestica (1) 18. 9. 99, (1) 7. 10. 99, (4) 12. 10. 99; auf Necrophorus vespillo (4) 11. 7. 00. A.

Vegesack: auf Necrophorus vespillo, humator. X. P.

34. M. tridentinus (G. et R. Can.).

Unter einem Brett im Hühnerhof (1 Deut.) 26. 8. 01.

Vegesack: Nest von Talpa europaea. III. P.

Cyrtolaelaps Berl.

35. C. nemorensis (C. L. Koch).

Unter faulendem Holz, hinter Finkenau (1 ㅇ) 24. 8. 01.

Gamasellus Berl.

36. G. spinipis (Oudms.).

Unter feuchten Steinen, hinter der Anstaltsmauer (1 Deut.) 1. 9.01 .

Haemogamasus Berl.

$\dagger$ 37. H. hirsutus Berl.

Vegesack: auf Talpa europaea und in dessen Nest. III. P. $\dagger$ 38. H. michaeli Oudms.

Vegesack: auf Talpa europaea, Mus silvaticus. X. P.

Laelaptinae.

Laelaps C. L. Koch.

39. L. agilis C. L. Koch.

Hinter der Anstaltsmauer, auf Arvicola arvalis (3 +) 4. 10. 02.

Vegesack: auf Arvicola arvalis (24); Nest von Mus minutus

(ð) 28. 8.96. P. - Auf Mus silvaticus, Arvicola arvalis. II. III. P.

Hypoaspis Can.

40. H. limbata (C. L. Koch).

Unter einem Brett, im Hühnerhof (2 $\sigma^{\top}, 3$ \&) 26. 801 . Unter faulendem Holz und Blättern, Hühnerhof (1 $\left.\sigma^{\top}\right)$ 10.9. 92. Auf Mus musculus, Wohnhaus (3 \&) 16. 9. 02. - Auf Arvicola arvalis, hinter der Anstaltsmauer (1 $\sigma^{\top}, 3$ Deut.) 4. 10. 02.

41. H. Iubrica Oudms, et Vgts.

(Taf. XVIII, Fig. 104-110.)

H. lubrica Oudms, et Vgts.: Zool. Anz. 27, p. 654 (14. 6. 1904).

Weibchen. Länge: $630 \mu$. Farbe: licht strohbraun. Gestalt wie bei Hypoaspis hermaphroditoides Oudms., mit welcher 
diese Art nahe verwandt ist; sie besitzt jedoch eine Andeutung von Schultern, welche die Vergleichsspezies nicht hat. Textur: schuppig auf den Schildern, fein gefaltet in den weichen Teilen; dorsal glatt und glänzend.

Rückenseite (Fig. 104) von einem Schilde gedeckt. Die Haare, in gewöhnlicher Zahl und Stellung, sind fein, kurz und glatt. Zwei Vertikalhaare nach vorne gerichtet. Keine deutlichen Schulterhaare.

Bauchseite. Tritosternum (Fig. 106) gewöhnlich, ziemlich lang, vorne ziemlich schmal. Es ist ein Prosternalschild vorhanden (Fig. 105), welches den ganzen Raum zwischen dem Tritosternum und dem Sternalschild einnimmt. Sternalschild, Metasternal- und Pedalschilder mit einander verwachsen. Hintere Kante des Sternometasternalteils ein wenig ausgebuchtet. Genitoventralschild umgekehrt birnförmig, vorne ein wenig über dem Sternometasternalschilde liegend, hinten nicht bis zur Mitte des Bauches sich erstreckend, eine grosse Strecke vom Analschilde entfernt. Analschild oval, Spitze nach hinten, mit den gewöhnlichen 3 Haaren und dem Cribrum. Peritrematalschilder sehr schmal, nur in ihrer hinteren Hälfte sichtbar, sich nach hinten ein wenig an den Foveolae pedales IV vorbei erstreckend und hier mit einer stumpfen Spitze endigend. Inguinalschilder klein. Haare fein und glatt. Ausser den gewöhnlichen Haaren auf den Schildern umgeben 4 Paar das Ventralschild, von denen das vorderste Paar ausserordentlich klein ist; 4 weitere Paare auf dem Bauche.

Epistom (Fig. 107) gerundet, höchstens mit einer medianen winzigen Spitze.

M andibeln kurz, ungefähr $240 \mu$ lang. Scheren (Fig. 108) kurz, gedrungen. Ob'erkiefer mit ungefähr 3 Schneide- und 2 Eckzähnen; keine Backenzähne. Sinnesorgan zwischen den Schneide- und Eckzähnen lanzettförmig, ziemlich breit. Sinnesorgan an der Basis des Oberkiefers sehr klein. Unterkiefer (Telotarsus) mit 1 Schneide- und 2 Eckzähnen, weit nach hinten; keine Backenzähne. Pulvillum: eine Reihe divergierender Haare.

Maxillen. Hypostom (Fig. 106 und 107) länglich, viel länger als bei $H$. hermaphroditoides. Hörner lang und schlank, dicht beisammen. Innere Malae sehr durchsichtig, nur unter sehr starker Vergrösserung sichtbar; die zwei basalen Zipfel breit, distal mit 6 Zipfelchen und an unsere beiden Arme erinnernd, wenn wir dieselben hoch über unserm Haupte gegeneinander beugen. Die übrigen Zipfel sehr fein, nicht an den Spitzen der Hörner vorbeigehend. Lingua (Fig. 106) gewöhnlich. Palpen: dorsal ohne etwas Eigentümliches; ventral (Fig. 110): Genu intern mit 2 durchsichtigen stabförmigen Haaren; Tarsus mit dem gewöhnlichen dreispaltigen Haare.

Beine 512 resp. 400, 400 und $512 \mu$ lang, schlank, selbst Beine II. Femur I dorsal mit einem kleinen dornförmigen Haare; Femur II ebenso distal; Femur IV mit 2 ebensolchen Haaren, einem 
in der Mitte und einem distal. Auch ventral haben die Beine, besonders Beine II einige dornförmige Haare.

Fundort: unter einem auf der Erde liegendem Brett im Hühnerhof (1 ㅇ) 26. 8. 01. - Type in coll. Oudemans.

\section{H. pavida (C. L. Koch).}

Unter feuchten Steinen, hinter der Anstaltsmauer (1) 15. 9.01. In feuchtem Moos, am Grunde von Melchers' Mauer (1 Deut., 1 \&) 16. 4. 01 .

\section{$\dagger$ 43. H. arcualis (C. L. Koch).}

Vegesack: Nest von Talpa europaea, auf Mus silvaticus, Arvicola arvalis, Talpa europaea. II, III, X. P.

$\dagger$ 44. H. fuscicolens Oudms.

Bremen: auf Bombus terrestris, hortorum; Psithyrus vestalis. IV. A.

$\dagger$ 45. H. talpae Oudms.

Vegesack: auf Talpa europaea. P.

Poecilochirus G. et R. Can.

46. P. fimetarius (J. Müll.).

An Knochen, hinter der Anstaltsmauer (1) 20. 3. 02.

Seiulus Berl.

47. S. hirsutus (C. L. Koch).

An der "alten" Weser aus Anspülicht gesiebt (4) 19. 9. 01. Hausgarten, auf einem Staphyliniden (2) 20. 9. 01.

48. S. levis Oudms. et Vgts.

(Taf. XVIII, Fig. 111--116.)

S. levis Oudms. et Vgts.: Zool. Anz. 27, p. 655 (14. 6. 1904).

Weibchen. Länge: $470-560 \mu$, an 4 Individuen gemessen. Farbe: licht strohgelb. Textur: fein geschuppt auf den Schildern, fein gefaltet in den weichen Teilen. Gestalt oval, Spitze nach vorne, geschultert, vorne stumpf gerundet, hinten schön gerundet, hinter den Schultern leicht eingebuchtet, dann in der hinteren Hälfte breiter.

Rückenseite (Fig. 111) von einem Schilde gedeckt, welches ganz vorne mit den dorsalen Teilen der Peritrematalschilder verwachsen ist. Haare an den gewöhnlichen Stellen, sehr klein.

Bauchseite. Tritosternum (Fig. 113) sehr belehrend, da es uns zeigt, dass die sogenannten Zipfel oder Spitzenhaare in Wahrheit nur das Tritosternum selbst sind; platt und tiefgespalten; jeder Gabelast beiderseits behaart oder gebärtet; die Basis ist klein; jeder der Zipfel ist anfangs schmal, dann breiter und endlich langsam an Breite abnehmend. Sternalschild (Fig. 112) etwas länger als breit, hinten gerade. Genitalschild vorne gerundet, in der Mitte eingeschnitten, nicht auf dem Sternalschilde liegend; 
glockenförmig; seine Schuppen sind so gelagert, dass man hinter dem vorderen Einschnitt eine Höhle zu sehen meint. Ventrianalschild breit, gerundet, nur mit 4 Paar kleiner Haare auf dem ventralen Teil, und mit den 3 gewöhnlichen Circumanalhaaren; mit einem nicht sehr tiefen Einschnitte an beiden Seiten des Anus, und mit breitem Cribrum. Peritrematalschilder breit, mit dem breiten Peritrema in der inneren Hälfte, hinten nach innen in ein Dreieck verlängert, welches sich selbst bis hinter Coxae IV erstreckt und offenbar mit einem dreieckigen, hinten gerundeten Metapodialschilde verwachsen ist. Pedalschilder rudimentär, nur durch Stückchen repräsentiert, welche an der Aussenseite der Foveolae pedales liegen. Haare sehr klein.

Epistom (Fig. 111) gerundet.

Mandibeln kurz, wenn ganz eingezogen, sich bis zum Sternalschilde erstreckend. Scheren (Fig. 114) ohne Sinnesorgane (soweit zu sehen war; sie können jedoch bei der Exstirpation der Mandibeln mutiliert sein). Oberkiefer mit 6 sägezahnähnlichen Zähnchen hinter dem starken gebogenen vorderen Schneidezahn, so dass kein Unterschied vorhanden ist zwischen den 3 (?) Schneideund den 3 (?) Eckzähnen. Unterkiefer (Telotarsus) mit 1 Schneidezahn und 2 nach hinten gebogenen Eckzähnen(?). Pulvillum: eine Reihe kleiner Haare an jeder Seite.

Maxillen. Hypostom (Fig. 115) mit normalen Hörnern und 2 einfachen inneren Malae, welche proximal kaum gefranst sind. In der langen medianen Spalte des Capitulums 7 Querreihen von je 3 winzig kleinen dreieckigen Anhängen (in der Figur nur durch Punkte angedeutet), welche ihre Spitzen nach vorne gerichtet haben. Palpen ventral (Fig. 116): Trochanter mit 2 Borsten; Femur extern mit einer Borste, intern mit einem platten, distal schief abgeschnittenem Haare; Genu intern mit 2 platten Haaren, von denen das eine distal schief abgeschnitten, das andere distal abgerundet ist; Tibia gewöhnlich; Tarsus mit der proximalen internen zweiästigen (nicht dreiästigen) Gabel.

Beine kürzer als der Körper, schlank, mit deutlichen Basifemora und Basitarsi, kurzen Praetarsi, kleinen Haftnäpfchen, kleinen Klauen, kleinen Haaren.

Fundort: unter einem Ziegelstein, im Hühnerhof (1 $q$ ) 9. 9. 01. - An der „alten“ Weser, aus Anspülicht gesiebt (4 + ) 19. 9. 01. - Type in coll. Oudemans.

\section{Euiphis Berl.}

(Redia. vol. I. fase. 2. p. 242; Dec. 1903.)

Syn.: Iphidoides Oudms. (Entom. Ber. p. 140; 1. 3. 1904).

49. E. halleri (G. et R Can.).

Unter feuchten Steinen, hinter der Anstaltsmauer (1 Deut., 4 q $)$ 15. 9. 01. - Auf Aphodius fimetarius, Blockland (6 Deut., 11 ㅇ) 
13. 4. 02; Sandberg (2 ㅇ) 5. 9. 02. - Auf Aphodius inquinatus, Blockland (1 Deut.) 26. 9. 02.

Vegesack: auf Vesperugo serotinus. V. P.

50. E. ostrinus (C. L. Koch).

Oberneuland: Jürgens Holz, unter trockener auf der Erde liegender Baumrinde (1 q) 4. 10. 01.

Melichares Hering.

51. M. agilis Her.

An trocknen Feigen (2 Nph.) 9. 01.

Dermanyssinae.

Dermanyssus Dugès.

52. D. gallinae (Degeer).

Wohnzimmer, an und in einem Kanarienvogel-Käfige $(\infty)$ 6. 03. [Zweimal frei umherlaufend angetroffen, zwischen Büchern 29. 9. 02 (1 ㅇ), 30. 10. 02 (1 우)].

Liponyssus Kolenati.

$\dagger$ 53. L. chelophorus Oudms.

Vegesack: Nest von Mus minutus (2 Nph.) 28. 8. 96. P.

$\dagger$ 54. L. arcuatus (C. L. Koch).

Ebenda: auf Vespertilio murinus (11). P.

$\dagger$ 55. L. albatus (C. L. Koch).

Ebenda: auf Talpa europaea. VI, VII, X. P.

$\uparrow 56$. L. albato-affinis Oudms.

Ebenda: auf Arvicola arvalis. IX. P.

$$
\dagger \text { 57. L. musculi (C. L. Koch). }
$$

Ebenda: auf Vesperugo serotinus (22 Nph., 1 ð. 5 우) 9. 96; Plecotus auritus, V. pipistrellus. V-IX. P.

\section{$\dagger 58$. L. Iepidopeltes Klti.} auritus. P.

Ebenda: auf Vesperugo pipistrellus, Vespertilio murinus, Plecotus $\dagger$ 59. L. Iobatus Klti.

Ebenda: auf Vesperugo noctula, V. pipistrellus, Plecotus auritus. IV, VI, VII. P.

$$
\dagger \text { 60. L. kolenatii Oudms. }
$$

Ebenda: auf Vesperugo pipistrellus. VII. P. 


\section{Spinturnicinae.}

Spinturnix v. Heyd.

$\dagger$ 61. S. vespertilionis (L.).

Vegesack: auf Vesperugo serotinus, Vespertilio murinus (11). P.

$\dagger$ 62. S. carnifex (C. L. Koch).

Ebenda: auf Vesperugo noctula. P.

$\dagger$ 63. S. plecoti Oudms.

Ebenda: auf Plecotus auritus. P.

\section{Metaparasitinae.}

Metaparasitinae Oudms. et Vgts. n. subfam.: Zool. Anz. 27, p. 655 (14. 6. 1904).

Bekanntlich werden die Parasitidae in zwei Gruppen eingeteilt, je nachdem die Genitalöffnung des $\sigma^{\star}$ vor oder in dem Sternalschilde liegt. Berlese machte zuerst diese Einteilung und benutzte selbst den Ausdruck: „in der Mitte des Sternalschildes“. Mit der Entdeckung des Rhodacarus roseus Oudms. war dieser Terminus einfach zu ändern in: „im Sternalschilde“, da bei dieser Art die Öffnung weit vor der "Mitte“ und in der Nähe des Vorderrandes des Sternalschildes gelegen ist. Die Gattung Rhodacarus Oudms. bildet also einen „Übergang“ zwischen der ersten und zweiten Gruppe Berleses.

Hier haben wir nun ein ganz anderes Tier vor uns, bei welchem, wie bei dem Rhodacarinae, das Männchen die Genitalöffnung beim Vorderrande des Sternalschildes trägt (Fig. 118). Der Unterschied ist aber so gross, dass wir wohl berechtigt sind, eine neue Unterfamilie, und zwar unter dem Namen Metaparasitinae, zu begründen, deren Charaktere folgende sind: Parasitidae, deren Männchen die Genitalöffnung im Sternalschilde trägt, und zwar in der Nähe des Vorderrandes. Gestalt: Parasitus-artig (Fig. 117). Der Name Metaparasitinae wurde gewählt, da diese Gruppe für jünger zu halten ist als die Parasitinae, deren Männchen die Genitalöffnung vor dem Sternalschilde tragen; diese Stellung der Genitalöffnung ist offenbar eine primitivere.

\section{Metaparasitus Oudms. et Vgts.}

Metaparasitus Oudms. et Vgts, n. gen.: Zool. Anz. 27, p. 655 (14. 6. 1904).

$$
\text { (Taf. XIX, Fig. 117-124.) }
$$

Die Charaktere dieser Gattung sind im allgemeinen dieselben wie die von Parasitus Latr., mit den Unterschieden, dass die männliche Genitalöffnung in dem Sternalschilde gelegen ist, unweit des Vorderrandes des Schildes (Fig. 118); dass das männliche Copulationsorgan frei und in der Basis des Unterkiefers (der Schere) 
eingepflanzt ist (Fig. 121), dass die Gabel des Tarsus der Palpen zweizinkig ist (Fig. 124,5) und dass der Tarsus der Palpen mit noch anderen Anhängen versehen ist (Fig. 123). - Weibchen unbekannt.

\section{M. suboles Oudms. et Vgts.}

(Taf. XIX, Fig. 117-124.)

M. suboles Oudms. et Vgts.: Zool. Anz. 27, p. 655 (14. 6. 1904).

Männchen. Länge: $600 \mu$. Gestalt oval, fast gleich gerundet an den beiden Enden, nur wenig geschultert, ungefähr halb so breit als lang. Farbe wie bei Parasitus. Textur: geschuppt in den harten, fein gefaltet in den weichen Teilen.

Rückenseite (Fig. 117) mit deutlicher Grenze zwischen Vorder- und Hinterschild. Alle Haare sind kurze scharfspitzige Borsten, in gewöhnlicher Zahl und Stellung. Keine Schulterhaare. Über den Coxae I werden die Peritremata dorsal, wo sie das Capitulum erreichen.

Bauchseite. Tritosternum (Fig. 119) lang, in zwei Zipfeln endend, im proximalen Drittel seitlich mit einer sehr kleinen internen Chitinisierung, ein Gelenk nachahmend, im mittleren Drittel seitlich mit ungefähr zwei kleinen Härchen, distal ebenso. Keine Jugularschilder (Fig. 118). Alle übrigen Schilder verwachsen. Genitalöffnung ungefähr ebenso weit vom Vorderrande des Sternalteiles erweitert, als ihre eigene Breite beträgt, so dass das erste Sternalhaarenpaar vor der Öffnnng steht. Haare nicht so borstenförmig wie auf dem Rücken; 3 Paar im Sternalteile, 1 Paar im Metasternalteile, 1 Paar im Genitalteile, 1 Paar im vorderen und 5 Paar im hinteren Bauchteile, 5 Paar im hinteren Saum; die 3 Circumanalhaare sind winzige gebogene Borsten. Cribrum dorsal (Fig. 117).

Epistom (Fig. 120) dreispitzig; jede Spitze kurz, breit, distal gesägt; die Mittelspitze kürzer als die Seitenspitze. Keine Styli!

Mandibeln kurz; wenn ganz eingezogen, erreichen sie das Sternalschild. Scheren (Fig. 121) mit den gewöhnlichen Sinnesorganen; Oberkiefer mit 2 kleinen Schneidezähnen und 1 kleinen Eckzahn; Unterkiefer mit hoher Basis, 1 starken Schneidezahn und 2 kleinen Eckzähnen. Copulationsorgan stilettförmig, wenig gebogen, an der Basis des Kiefers befestigt! Kein Pulvillum!

Maxillen. Hörner des Hypostoms (Fig. 119) normal. Innere Malae je in zwei Zipfel geteilt; die externen Zipfel breit, dreieckig, nach den Hörnern gerichtet und mit diesen scheinbar Zangen bildend; die internen Malae lang, wenig auswärts gebogen. Ausserdem bemerken wir, das Mikroskop niedriger stellend, ein drittes Paar durchsichtiger Blätter, nach innen gebogen und einander vor den inneren Zipfeln begegnend. Keine Franse! Palpen: dorsal (Fig. 117): Femur distal und intern mit dem gewöhnlichen durchsichtigen winzigen Däumling, proximal und median mit dem 
nach innen und vorne gebogenen Haare. Ventral (Fig. 122): Trochanter distal und intern mit dem gewöhnlichen durchsichtigen dreieckigen Zähnchen; Femur distal und intern mit 2 Höckerchen und einem wenig gebogenen, messerförmigen, durchsichtigen Haare, dessen stumpfes Ende gesägt ist (Fig, 123, ${ }_{1}$ ); Genu mit den gewöhnlichen internen platten Haaren (Fig. 123, ${ }_{2}, 3$, stark vergrössert); Tibia mit den 2 gewöhnlichen distalen Haaren, von denen jedoch das interne lanzettförmig ist (Fig. 123,4); Tarsus mit einer zweizinkigen Gabel (Fig. 123,5), von deren Zinken die grössere mit einem schmalen durchsichtigen Saume, die kleinere mit einem breiteren dreilappigen Saume versehen ist. Tarsus ausserdem mit einem fast viereckigen durchsichtigen Blatte, welches an die Tarsalanhänge von Pachylaelaps erinnert.

Beine (Fig. 117) schlank, 930 resp. 630, 660 und $1050 \mu$ lang; typisch wie die des Parasitus. Beine II ohne ventrale Höcker, auch nicht im mindesten dicker als die übrigen Beine. Praetarsus IV (Fig. 124): Tarsalhaare länger als der Praetarsus; Distalhaare deutlich; superunguinale Haftscheibchen dreilappig; subunguinale Haftblase klein, kugelförmig. Tarsus. IV distal (Fig. 124) mit 8 winzigen Dörnchen.

Fundort: unter Steinen. - Type in coll. Oudemans.

\section{Ascainae.}

Asca v. Heyd.

65. A. peltata (C. L. Koch).

Vorm Blocklande, aus Heu gesiebt am Grunde einer Heudieme (1 우) 30. 9. 01 .

66. A. togata (C. L. Koch).

Unter Ziegelsteinen beim Adelenstift (1 Lv., 2 우) 4. 9. 01. $\dagger$ 67. A. affinis Oudms.

Vegesack: auf Talpa europaea. P.

\section{Uropodinae.}

Neoseius Oudms.

$\dagger$ 68. N. novus (Oudms.).

Vegesack: auf Necrophorus vespillo, humator. X. P. Polyaspis Berl.

$\uparrow$ 69. P. patavinus G. et R. Can.

Bremen: auf Criocephalus ferus Kr. (11) 31. 8. 99. A.

Uropoda Latr.

70. U. ovalis (C. L. Koch).

Unter Steinen: an der „alten“ Weser, bei der kleinen Brücke (1 ð, 1 ㅇ) 11. 4.01; beim "Adelenstift (24) 4.9.01; hinter der 
Anstaltsmauer (1 ㅇ) 9. 4. 02. - Vorm Blocklande, aus Heu gesiebt am Grunde einer Heudieme (1) 30.9. 01; ebenda, aus einem Unkrauthaufen gesiebt (1 \&) 21.9 .01$.

Bremen: auf Criocephalus ferus Kr. (6) 31. 8. 99. A.

\section{$\dagger 71$. U. alfkeni Oudms.}

Bremen: auf Prosopis brevicornis. II. A.

72. U. levisetosa Oudms, et Vgts.

(Taf. XIX, Fig. 125-136.) 1904).

U. levisetosa Oudms. et Vgts.: Zool. Anz. 27, p. 655 (14. 6.

Deutonympha. Länge: 700, Breite: $580 \mu$. Farbe: dunkel strohbraun. Gestalt: kurz oval, Spitze nach vorn. Textur: poliert (nicht geschuppt) auf den Schildern, mit weniger chitinisierten runden Fleckchen (welche Grübchen imitieren) im mittleren Teile des Dorsal- (Fig. 125), Sternal- und Ventrianalschildes (Fig. 126, 129) und mit ähnlichen polygonalen Fleckchen auf den Pedal-, Peritrematal- und Metapodialschildern. Weiche Teile fein gefaltet, nämlich ein Band zwischen dem ventral umgebogenen Rande des Dorsalschildes einerseits und den Peritrematal- Metapodial- und Ventrianalschildern anderseits (Fig. 126, 129). Schöne Zeichnungen finden sich auch auf der Ventralseite der Coxae. Rückenseite (Fig. 125) mit nur einem Schilde, welches in der Mitte konvex ist und im Saume platt oder kaum eine Rinne bildet. Der konvexe mittlere Teil ist mit zahlreichen weniger chitinisierten runden Fleckchen versehen, welche Grübchen imitieren, und mit zahlreichen gebogenen, dicken, glatten Haaren (Fig. 127). Der platte oder kaum rinnenförmige Saum ist glatt, kaum heller gefärbt und nur mit einer marginalen Reihe von Härchen versehen; er wird weniger breit nach hinten, wo er selbst median verschwindet. Dieser Saum repräsentiert selbstverständlich das Ringschild, aber die beiden Schilder sind miteinander verwachsen.

Bauchseite. Tritosternum (Fig. 128) sonderbar geformt; es besteht nämlich aus einem platten, fast viereckigen Basalteil und einer mit kleinen Dörnchen versehenen stabförmigen Verlängerung, welche mit zwei Härchen endet. Sternalschild (Fig. 126) lang, gerade in der Mitte des Körpers, so dass die Entfernung seines Vorderrandes vom Vorderrande des Körpers dieselbe ist wie die seines Hinterrandes vom Hinterrande des Körpers; es ist mit zahlreichen runden Grübchen (?) und den gewöhnlichen 4 Paar kleiner Härchen versehen. Ventrianalschild klein, dreieckig, mit gerundeten Rändern und Ecken, mit nur wenigen runden Grübchen in den vorderen Ecken versehen, und mit 4 Härchen hinter dem Sternalschilde, 2 Härchen in den Vorderecken und 2 vor dem Anus. Jede Analklappe trägt auch ein Härchen. Pedalschilder deutlich zwischen den Coxae (welche ziemlich weit voneinander stehen) und sichtbar rund um die Foveolae pedales II und III, nicht um die 
Foveola pedalis IV, wo sie mit den Metapodialschildern verwachsen sind. Metapodialschilder deutlich begrenzt von den Peritrematalschildern durch eine Linie, welche von der Foveola pedalis IV vorwärts verläuft, dann plötzlich nach aussen umbiegt; sie umgeben die Beingrube IV. Die Peritrematalschilder nehmen den Raum ein zwischen den Metapodial- und Pedalschildern und der weichen Haut (oben bei Textur erwähnt); sie umfassen die Beingruben II und III. Pedal-, Metapodial- und Peritrematalschilder mit polygonalen, weniger chitinisierten Fleckchen versehen, welche Gruben imitieren und einander berühren (siehe auch Fig. 129). Das Dorsalschild biegt sich ventralwärts um und bildet hier einen Saum, welcher aus zahlreichen viereckigen Stückchen besteht, jedes mit einem Härchen versehen (Fig. 129), welches die Kante nicht erreicht; zufällig kommen auch 2 solcher Härchen in einem Stückchen vor. Das Stigma liegt in der Vorderecke der Beingrube III. Das Peritrema setzt sich nach hinten fort, am inneren Rande der Fussgrube III entlang, bis es fast die Foveola pedalis III erreicht; nach vorne biegt es sich erst auswärts bis zur weichen Haut, geht an dieser entlang, biegt sich dann einwärts, kommt damit an die Beingrube II, wo es nach vorne umbiegt und mit einigen Schlängelungen die Vorderkante des Leibes ungefähr über Bein I erreicht.

Tectum (Fig. 130) dunkelbraun, mit lanzettförmigem medianem Dorn.

Epistom (Fig. 131) gewöhnlich. Der lange Zipfel hat nur drei Zipfelchen an jeder Seite. Merkwürdig ist, dass das Epistoma die beiden Styli (Fig. 131 b) umfasst.

Mandibeln (Fig. 132) klein, nur wenig am Sternalschilde vorbeireichend, wenn sie ganz eingezogen sind. Trochanterofemur kurz und dick; Tibiotarsale lang, langsam sich verschmälernd. Scheren (Fig. 133) winzig, ohne Sinnesorgane. Oberkiefer mit 5 stumpfen und gerundeten Zähnchen, welche von ziemlich gleicher Grösse sind. Unterkiefer mit 4 solcher Zähnchen, welche gerade in die Intervalle der Zähnchen des Oberkiefers passen; der vorderste (Schneide-) Zahn schmal, der dritte (Eck-) Zahn ein wenig höher als die übrigen und etwas nach hinten gerichtet.

Maxillen. Merkwürdig ist, dass auf der Rückenseite des Capitulums (Fig. 131) eine Grenzlinie zu sehen war zwischen dem Coxalteil (a) der Maxillen einerseits und dem Mittelfelde des Capitulums mit dem Epistoma anderseits, so dass dieses Mittelfeld mit dem Epistoma wahrscheinlich eine Oberlippe repräsentiert. An der Bauchseite des Capitulums (Fig. 134) begegnen wir einer zweiten merkw ürdigen Erscheinung, nämlich: hier sind 5 Paar Haare statt 4! Ungefähr in der Mitte ein Paar dicke, gebogene, behaarte Haare; mehr nach vorne ein Paar längere dicke Haare, jedes nur mit 3 Dörnchen versehen; ferner ein Paar in drei Äste gespaltene Haare (siehe auch Fig. 135); dann anstatt des vierten Paares ein starker Auswuchs, welcher mit $\mathrm{zwei}$ Haaren (statt mit einem) endet (s. auch Fig. 135). Eine dritte Merkwürdigkeit 
ist die Anwesenheit dieses Auswuchses, welcher in der rechten Hälfte der Fig. 135 als abgeschnitten gezeichnet ist, um besser die Details der Malae zu zeigen. Hier stossen wir auf eine vierte Merkwürdigkeit, nämlich: die Hörner sind platt, fast gleichbreit der ganzen Länge nach, distal gespalten (wie ein Fischmaul) und mit zwei kleinen dreieckigen Zähnchen versehen, einem in der Mitte der Aussenkante und einem ventralen in der Nähe der Mitte der distalen Hälfte der Innenkante. Eine fünfte Merkwürdigkeit ist die Gestalt der inneren Malae, welche Hörner oder Aussenmalae imitieren, ohne jeden Zipfel oder Franse. Ventral besitzen sie eine zweite hornförmige Chitinisierung, welche nur die Hälfte der Länge erreicht da, wo sie plötzlich etwas einwärts gebogen sind. Palpen. Wie oben schon erwähnt, ist die Coxa dorsal (Fig. 131 a) deutlich von dem Mittelfelde des Capitulums unterschieden. Ventral (Fig. 136): Trochanter distal mit zwei Haaren, von denen das eine nach hinten gerichtet und mit Dörnchen besetzt ist, während das andere in drei Äste gespalten ist und auf einem Höckerchen steht; Femur nur mit einem Dorne oder starker Borste; Genu mit einem feinen Haare extern und einer Borste intern; Tibia mit den gewöhnlichen zwei distalen Borsten: Tarsus mit den gewöhnlichen vielen Haaren, und proximal und intern mit einer zweiästigen (nicht dreiästigen) Gabel.

Beine gewöhnlich, kurz, mit den gewöhnlichen blattförmigen Anhängen (einer an jedem Femur), mit deutlichen Basitarsi und mit einem kleinen Dörnchen an den Tarsi II und III.

Fundort: unter einem Stein bei der kl. Brücke über die „alte" Weser (1 Deut.) 11. 4. 01. - Type in coll. Oudemans.

Cilliba v. Heyd.

73. C. vegetans (Ant. Dug.).

Unter Holz, im Hühnerhof (1 Deut.) 26. 8. 01; Hausgarten, unter einem Brett (2 Deut.) 6. 10. 01. - Unter feuchten Steinen, hinter der Anstaltsmauer (9 Deut.) 15. 9. 01. - Auf Aphodius fimetarius, Sandberg (7 Deut.) 5. 9. 02. - Auf Geotrupes stercorarius, Blockland (3 Deut.) 10.9. 02.

\section{Ixodidae.}

Argasinae.

A rgas Latr.

\section{$\dagger$ 74. A. vespertiliones (Latr.).}

Vegesack: auf Vesperugo serotinus (Lv.) 9. 96; Vesperugo noctula IV, V, VIII. P.

Ixodinae.

Ix odes Latr.

$\dagger 75$. I. ricinus (L.).

Vegesack: auf Mus silvaticus. II. P. 


\title{
Bdellidae.
}

Tydinae.

\author{
Tydeus C. L. Koch. \\ 76. T. foliorum (Schrk.).
}

Oberneuland: Jürgens Holz; unter trockener auf der Erde liegender Baumrinde (1) 4. 10. 01.

Poecilophysinae.

Poecilophysis Cambr.

77. P. celer (Herm.).

Unter Ziegelsteinen beim Adelenstift (1) 4. 9. 01.

78. P. pratensis (C. L. Koch).

Unter Ziegelsteinen bei der Mühle (2) 4. 9. 01; unter feuchten Steinen hinter der Anstaltsmauer (3) 15. 9. 01, (1) 9. 4. 02.

Eupodinae.

Eupodes C. L. Koch.

79. E. striola C. L. Koch.

Unter feuchten Steinen, Ziegelsteinen etc.: Hühnerhof (2) 23. 8. 01; hinter Finkenau (1) 24. 8. 01; bei der Mühle (1) 4. 9. 01; auf einem Hofe (1) 29. 9. 01; hinter der Anstaltsmauer (9) 15. 9. 01. - Unter faulendem Holz und Blättern; Hühnerhof (1) 10. 9. 02. - An der „alten" Weser, aus Anspülicht gesiebt (2) 19. 9. 01. - Vorm Blocklande, aus einem Unkrauthaufen gesiebt (1) 21.9. 01.

\section{Linopodes C. L. Koch. \\ 80. L. motatorius (L.).}

Unter feuchten Ziegelsteinen: hinter Finkenau (3) 24. 8. 01; hinter der Anstaltsmauer (1) 1. 9. 01, (1) 9. 4. 02; auf einem Hofe (11) 29. 9. 01. - Unter altem morschen Holz, Hühnerhof (2) 23. 8. 01.

Oberneuland: Jürgens Holz, unter auf der Erde liegender trockener Baumrinde (9) 4. 10. 01.

Penthalodes Murray.

81. P. ovalis (Ant. Dug.).

Weserdeich, unter Ziegelsteinen (11) 8. 9. 01.

Penthaleus C. L. Koch.

82. P. haematopus C. L. Koch.

Unter Ziegelsteinen bei der Mühle (4) 4. 9. 01; Hühnerhof (2) 9. 9. 01.

83. P. minor (R. Can.).

Unter Ziegelsteinen bei der Mühle (1) 4. 9. 01. 
Pachygnathinae.

Bimichaelia Thor.

(Michaelia Berl.).

84. B. angustana (Berl.).

Unter altem morschen Holz im Hühnerhof (1) 23. 8. 01.

Bdellinae.

Bdellla Latr.

85. B. Iongicornis (L.).

Unter feuchten Steinen: Hühnerhof (2) 23. 8. 01, (11) 9. 9. 01; hinter der Anstaltsmauer (1) 1. 9. 01, (1) 15.9.01; bei der Mühle (5) 4. 9. 01. - Unter morschem Holz: Hühnerhof (3) 23. 8. 01. Unter faulendem Holz und Blättern, Hühnerhof (5) 10. 9. 02.

86. B. Iapidaria Kram.

Unter Ziegelsteinen bei der Mühle (1) 4. 9. 01. - Vorm Blocklande, aus Heu gesiebt am Grunde einer Heudieme (4) 30. 9. 01 .

87. B. capillata Kram.

Unter Ziegelsteinen bei der Mühle (1) 4. 9. 01. - In Moos, Hausgarten (1) 20. 4. 01. - An der „alten" Weser, aus Anspülicht gesiebt (16) 19. 9. 01.

88. B. vulgaris (Herm.).

Unter Ziegelsteinen bei der Mühle (7) 4. 9. 01. - Von Gras gestreift, vorm Blocklande (1) 21. 9. 01.

89. B. silvatica Kram.

Unter Ziegelsteinen: bei der Mühle (3) 4. 9. 01; Weserdeich (6) 8. 9. 01 .

Cyta v. Heyd.

90. C. latirostris (Herm.).

Vorm Blocklande, aus Heu gesiebt am Grunde einer Heudieme (1) 30.9 .01 .

\section{Thrombidifiae.}

Anystinae.

Anystis v. Heyd.

91. A. baccarum (L.).

Unter Ziegelsteinen: bei der Mühle (1) 4. 9. 01; Weserdeich (2) 8. 9. 01. - Hausgarten, unter einem Blumentopf (1) 27. 9. 02. Hausgarten, in Moos (2) 20. 4. 01. - Unter auf der Erde liegender trockener Baumrinde, Sandberg (2) 27. 9. 02. - An der „alten“ Weser, aus Anspülicht gesiebt (7) 19. 9. 01. - Vorm Blocklande, 
aus einem Unkrauthauf $\lrcorner n$ gesiebt (1) 21. 9. 01; ebenda, aus Heu gesiebt am Grunde einer Heudieme (1) 30.9.01; ebenda, von Gras gestreift (4) 21.9. 01.

Vegesack: auf Vesperugo pipistrellus. VII. P.

Tarsotomus Berl.

92. T. comes Berl.

Hausgarten, in Moos (1) 20. 4. 01.

Tetronychinae.

Tetronychus Duf.

93. T. telarius (L.).

Unter feuchten Steinen, hinter der Anstaltsmauer (1 + \&) 1. 9. 01. - Hausgarten: auf der Unterseite von Himbeerblättern $(\infty)$,

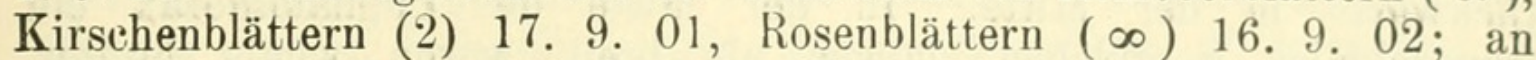
trockenem und faulendem Gurken-, Bohnenkraut usw. ( $\infty)$ 3. 10. 02. Wohnzimmer, an Spargelkraut (Asparagus sprengeri) (7) 12. 4. 02.

Bryobia C. L. Koch.

94. B. lapidum (Hammer).

(Tat. XIX, Fig. 137-138.)

1762. Acarus petrarum ruber, pedibus anticis longitudine corporis. Geoffr Hist. abrég. Ins. v. 2., p. 625, no. 10.

1804. Trombidium lapidum Hammer in Hermann's Mém. Apt. p. 49, t. 7, f. 7, 8, R, S. Type des Genus Petrobia Murray, 1877 (siehe unten).

1806. Gamasus (?) lapidum Latr. Gen. Crust. Ins. v. 1, p. 147. p. 125.

1817. Leptus lapidum Latr. in Cuvier Règne Anim. v. 3,

1818. Trombidium lapidum Oliv. Encycl. méth., tab. 347, f. $25,26,28,29$.

1829. Leptus lapidum Latr. in Cuv. Règn. Anim. v. 3, p. 290.

1834. Raphignathus lapidum Dugès in Ann. Se. Nat. ser. 2, v. 1, p. 15,24 .

1836. Leptus lapidum Latr. in Cuv. Règn. anim v. 3, p. 306.

1842. Raphignatus lapidum Koch, Übers. Arachn. Syst. v. 3, p. 57.

1849. Leptus lapidum Dugès et Miln. Edw. in Cuv. Règn. anim.; Arachn. p. 102.

1863. Trombidium lapidum Westw. in Entom. Monthl. Mag. v. 1, p. 170 .

1867. Trombidium lapidum Müller in Entom. Monthl. Mag. v. 5 , p. 71 . p. 118.

1877. Petrobia lapidum Murray, Econ. Entom.; Aptera, 
Endlich - nach einem Jahrhundert - ist diese Spezies zurückgefunden; Leider aber ist das einzige Exemplar während der Manipulation unter dem Präpariermikroskope bei der Behandlung mit Essigsäure verloren gegangen, so dass das Typen-Exemplar, nach dem die Zeichnungen angefertigt sind, nicht existiert.

Nymphe oder Erwachsene? Länge: $640 \mu$, Breite: $400 \mu$. F arbe: grün, selbst die Beine waren grün (Geoffroy und Hammer sahen rote Exemplare). Gestalt wie die der Bryobia cristata (Dugès) (= praetiosa C. L. Koch). Textu r: fein gefaltet, ausser einem trapezoidalen Schildchen, welches glatt ist.

Rückenseite (Fig. 137) in einen sogenannten Cephalothorax und ein Abdomen geteilt. Ersterer ungefähr ein Drittel der Körperlänge. Grenzlinie nicht gerade, sondern etwas gebuchtet, und zwar vorwärts bei den Schultern, hinter den Doppelaugen, und rückwärts in der Mitte. In der Mitte des Cephalothorax ein trapezoidales Schildchen, länger als breit, vorne wenig breiter, mit gerundeten Ecken. Vor diesem Schildchen zwei nach vorne gerichtete Vertikalhaare. Die Körperkante ist mit einer Reihe von Haaren versehen, welche senkrecht auf der Kante stehen; die Zahl derselben ist unbekannt, aber sicher sind in der Zeichnung kaum mehr als die richtige Zahl angegeben. Vor dem Cephalothorax befindet sich der gewöhnliche mediane Höcker. An jeder Seite dieses Höckers eine hornförmige Verlängerung der Peritremata von der Gestalt eines Zuckerhutes, welche, soweit ersichtlich war, distal geschlossen sind. Keine durchsichtige vierlappige Kopfzierde, wie bei Bryobia cristata (Dugès). Sollte diese Eigenschaft hinreichend sein, um ein Genus Petrobia Murray anzunehmen? - Die Haare (Fig. 138) sind auch nícht platt und fächerförmig, wie bei der Vergleichsspezies, sondern etwas kolbenförmig und mit winzigen Härchen versehen. - Die Beine sind kurz, selbst das erste Paar war nicht länger als der Körper.

Fundort: unter Steinen.

Vaterland: Deutschland: Strassburg; Oslebshausen: unter einem Ziegelstein im Hühnerhof (1) 9. 9. 01.

Gefunden von Geoffroy, Sulzer, Hammer und Voigts.

NB. Die Zeichnungen Sulzers (in Hermanns Mém. Apt. t. 7, fig. 7, 8, R, S) zeigen deutlich die zuckerhutförmigen PeritremaEnden zur Seite des medianen Höckers; sie werden aber nicht von Hammer (l. c. p. 49-51) erwähnt. Sulzer bildet jederseits 3 Augen ab und Hammer meldet auch deren 3. Bei unserm Exemplar schienen vicht 3 Augen vorhanden zu sein, daher sind in der Zeichnung nur 2 jederseits angegeben.

95. B. praetiosa C. L. Koch.

Unter Ziegelsteinen: Hühnerhof (3) 23. 8. 01, (12) 9. 9. 01. Von Gras gestreift, vorm Blocklande (11) 21. 9. 01. - Wohnzimmer, auf Asparagus sprengeri (1 Lv.) 12. 4. 02. 


\section{Cheletinae.}

Cheletes Latr.

96. Ch. eruditus (Schrk.).

Unter Holz im Hühnerhof (1 f) 26. 8. 01.

97. Ch. venustissimus C. L. Koch.

Vorm Blocklande, aus Heu gesiebt am Grunde einer Heudieme (30) 30. 9. 01.

$$
\text { Syringophilus Heller. }
$$

$\dagger$ 98. S. bipectinatus Heller.

Vegesack: auf Anas boschas (40) P. - Ist nach Poppe (1888) in Vegesack und Bremen auf Hühnern nur zweimal vorgekommen; sonst auf Anas boschas, Larus argentatus, Picus viridis, Hirundo riparia, Garrulus glandarius, Parus caudatus, Troglodytes parvulus, Turdus pilaris, Fringilla coelebs, Passer domesticus, P. montanus. P.

Myobia v. Heyd.

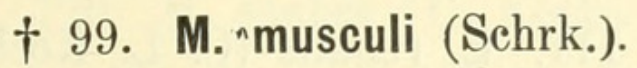

Bremer Gebiet: auf Mus musculus und silvaticus. P.

+100 . M. brevihamata Haller.

Ebenda: auf Talpa europaea. P.

101. M. Iemnina (C. L. Koch).

Vegesack: auf Arvicola arvalis; Mus silvaticus II, VIII, IX. P.

$\dagger$ 102. M. affinis Poppe.

Vegesack: „Krudop's Busch“, auf Mus musculus. P.

+ 103. M. ensifera Poppe.

Bröcken bei Vegesack: auf Mus decumanus. P.

$\dagger$ 104. M. claparèdei Poppe.

Bremer Gebiet: auf Sorex vulgaris. P.

$\dagger$ 105. M. elongata Poppe.

Ebenda: auf Sorex vulgaris. P.

Cunaxinae.

Cunaxa v. Heyd.

106. C. setirostris (Herm.).

Unter Ziegelsteinen, Hühnerhof (1) 23. 8. 01. - Vegesack: auf Vesperugo serotinus. VIII. P.

107. C. taurus (Kram.).

Oberneuland: Jürgens Holz, unter auf der Erde liegender trockener Baumrinde (1) 4. 10. 01. 
Thrombidiinae.

Thrombidium ${ }^{1}$ ) Fabr.

108. Thr. holosericeum (L.).

Unter Steinen bei der kleinen Brücke über die „alte“ Weser (1) 15. 4. 01.

109. Thr. purpureum C. L. Koch.

Unter Ziegelsteinen im Hühnerhof (1) 9. 9. 01.

Allothrombidium Berl.

$\dagger$ 110. A. fuliginosum (Herm.).

Badener Berge bei Achim: unter der Rinde von Abies excelsa

(3) 5. 4. 01. A. -

Vegesack: auf Plecotus auritus, Mus silvaticus, Talpa europaea. II. $\mathrm{X}$. P.

Erythraeinae.

Erythraeus Latr.

$\dagger$ 111. E. regalis (C. L. Koch).

Badener Berge bei Achim: unter der Rinde von Abies excelsa (1) 5. 4. $01 . \mathrm{A}$.

Belaustium v. Heyd.

112. B. miniatum (Herm.).

Vorm Blocklande, aus Heu gesiebt am Grunde einer Heudieme (1) 30.9. 01.

\section{$\dagger$ 113. B. murorum (Herm.).}

Lesum: auf Athous haemorrhoidalis (Lv.) 8. 6. 00. A.

A chorolophus Berl.

\section{A. nemorum (C. L. Koch).}

Unter altem morschen Holz, Hühnerhof (2) 23. 8. 01 . Unter Ziegelsteinen, ebenda (1) 9. 9. 01.

\section{A. ignotus (Oudms.).}

Auf Opilioniden (Opilio serripes etc.): Hausgarten (3 Lv.) 22. 8. 01; beim Adelenstift (47 Lv.) 4. 9. 01; Hühnerhof (5 Lv.) 10. 9. 02. - Unter einem Stein, Weserdeich (1 Lv.) 8. 9. 01 .

\section{Tarsonemidae.}

Tarsonemus Can. et Fanz.

$\dagger$ 116. T. soricicola Oudms.

Vegesack: auf Sorex vulgaris. II. P.

1) Vielfach wird dieser Gattungsname fälschlich Trombidium geschrieben; das Wort lautet griechisch: Эpoußíoıv! 
Pygmephorus Kram.

$\dagger$ 117. P. spinosus Kram.

Wie vorige: auf Mus silvaticus, Talpa europaea. II. P.

Disparipes Mich.

+118 . D. bombi Mich.

IV. A.

Bremen: auf Bombus terrestris, hortorum, Psithyrus vestalis,

\section{Oribatidae.}

Camisiinae.

Camisia v. Heyd.

119. C. biverrucata (C. L. Koch).

Unter Steinen hinter der Anstaltsmauer (2) 9. 4. 02.

Hermannia Nic.

120. H. scabra (L. Koch).

Hühnerhof, unter Ziegelsteinen (6) 23. 8. 01.

Hypochthonius C. L. Koch.

121. H. rufulus C. L. Koch.

Oberneuland: Jürgens Holz, unter auf der Erde liegender trockener Baumrinde (1 \&) 4. 10. 01.

Oribatinae.

Oribata Latr.

122. 0. clavipes (Herm.).

Unter Steinen bei der kleinen Brücke über die "alte" Weser

(2) 11. 4. 01. - Unter faulem Holz, hinter "Finkenau“ (2) 24. 8. 01 .
123.
0. nitens (C. L. Koch).

Unter Ziegelsteinen im Hühnerhof (2) 23. 8. 01.

Eremaeinae.

Liacarus Mich.

124. L. coracinus (C. L. Koch).

Unter Steinen bei der kleinen Brücke über die „alte“ Weser (2) 11. 4. 01 .

125. L. subterraneus (C. L. Koch).

Oberneuland: Jürgens Holz, unter auf der Erde liegender trockener Baumrinde (2) 4. 10. 01. 
Eremaeus C. L. Koch.

126. E. bipilis (Herm.).

Unter Steinen bei der kleinen Brücke über die „alte“ Weser (2) 11. 4. 01 .

127. E. Iucorum (C. L. Koch).

Unter Ziegelsteinen: bei der Mühle (3) 4. 9. 01; Hühnerhof (1) 9. 9. 01; hinter der Anstaltsmauer (1) 9. 4. 02.

\section{E. similis (Mich.).}

Unter feuchten Steinen: an der „alten“ Weser (1) 11. 4. 01; hinter der Anstaltsmauer (1) 1. 9. 01, (3) 9. 4. 02.

129. E. varius Oudms, et Vgts.

E. varius Oudms. et Vgts. n. nom.: Zool. Anz. 27, p. 656 (14. 6. 1904): „Diese Art wurde schon 5. Sept. 1900 von Oudemans unterschieden (Tijdschr. voor Entom. v. 43, p. 162), jedoch nur als eine Aberration oder Varietät angesehen. Sie gleicht $\boldsymbol{E}$. exilis (Nic.), hat aber keine Lamellarspitzen."

Unter feuchten Steinen: bei der kleinen Weserbrücke (1) 11. 4. 01; hinter der Anstaltsmauer (1) 1. 9. 01; Hühnerhof (1) 9. 9. 01 . -

Oberneuland: Jürgens Holz, unter auf der Erde liegender trockener Baumrinde (1) 4. 10. 01.

Banksia ${ }^{1}$ ) Oudms. et Vgts. n. nom.

(pro Kochia Oudms. 1900).

130. B. lata (Nic.).

Unter Steinen bei der kleinen Brücke über die „alte“ Weser (1) 15. 4. 01.

Cepheius C. L. Koch.

131. C. coriaceus (C. L. Koch).

Unter Steinen hinter der Anstaltsmauer (3) 9. 4. 02.

Scutovertex Mich.

132. S. ovalis (Berl.).

Unter feuchten Steinen: bei der kleinen Weserbrücke (1) 11. 4. 01; Hühnerhof (1) 23. 8. 01; hinter der Anstaltsmauer (2) 1. 9. 01. - Aus Anspülicht gesiebt, an der „alten“ Weser (1) 19. 9.01.

1) Der Gattungsname Kochia war bereits 1891 von Frech für eine Molluskengattung vergeben (Abh. Geol. Spezialk. Preuss. IX, 3, p. 72). Der Name Banksia nach Nathan Banks, dem bekannten amerikanischen Arachnologen. 


\section{Notaspidinae.}

Notaspis Herm.

133. N. gilvipes (C. L. Koch).

Unter Steinen hinter der Anstaltsmauer (5) 9. 4. 02.

134. N. orbicularis (C. L. Koch).

Unter Steinen bei der kleinen Weserbrücke (1 nph.) 11. 4. 01.

135. N. trimaculata (C. L. Koch).

Ebenda (1) 11. 4. 01. - Aus Anspülicht gesiebt, an der „alten" Weser (1) 19. 9. 01. - Von Gras gestreift, hinter der Anstaltsmauer (1) 21. 9. 01.

\section{N. humeralis Herm.}

Unter feuchten Steinen: bei der kleinen Weserbrücke (15) 11. 4. 01; hinter der Anstaltsmauer (2) 1. 9. 01; (3) 15. 9. 01; Hühnerhof (1) 9. 9. 01. -

Bremen: Bürgerpark, unter der Rinde von Quercus robur $(\infty)$. A.

137. N. quadricornuta (Mich.).

Unter Steinen hinter der Anstaltsmauer (1) 9. 4. 02.

138. N. alata Herm.

Wie vorige (5) 1.9. 01.

139. N. elimata (C. L. Koch).

Unter feuchten Steinen, bei der kleinen Weserbrücke (9) 11. 4. 01 .

\section{N. Iucasi (Nic.).}

Unter Steinen: bei der kleinen Weserbrücke (4) 11. 4. 01; bei der Mühle (2) 4. 9. 01. - Vorm Blocklande, aus einem Unkrauthaufen gesiebt (1) 21.9. 01.

Vegesack: Nest von Talpa europaea. III. P. ${ }^{1}$ )

$$
\text { Pelops C. L. Koch. }
$$

141. P. acromius (Herm.).

Unter Steinen, hinter der Anstaltsmauer (2) 9. 4. 02.

Phthiracarinae.

Hoploderma Mich.

142. H. dasypus (Ant. Dug.).

Oberneuland: Jürgens Holz, unter trockener auf der Erde liegender Baumrinde (4) 4. 10. 01.

1) Die von Poppe bei Vegesack gefundenen Exemplare wurden von Oudemans fälschlich als pallidula (C. L. Koch) bezeichnet, in Tijdschr. d. Ned. Dierk. Vereen. 2. ser. v. 8, p. 72. 


\section{Acaridae.}

Tyroglyphinae.

Nanacarus Oudms.

$\dagger$ 143. N. minutus (Oudms.).

Vegesack: auf Vesperugo serotinus, pipistrellus, Sorex vulgaris. II. VIII. P.

\section{Tyroglyphus Latr.}

\section{T. putrescentiae (Schrk.).}

Unter feuchten Steinen, hinter der Anstaltsmauer (6) 1.9.01, (2) 15. 9. 01. - Unter faulem Holz, Hühnerhof (1) 10. 9. 02. Aus Anspülicht gesiebt, an der „alten" Weser (1) 19. 9. 01. An altem Rahmkäse, Wohnhaus ( $\infty)$ 28. 10. 02.

Vegesack: an Schinken $(\infty)$ P.

Aleurobius Can.

\section{A. farinae (L.).}

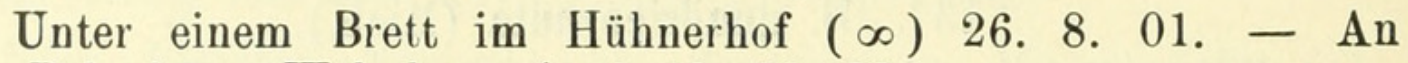
altem Rahmkäse, Wohnhaus ( $\infty)$ 28. 10. 02.

Vegesack: in einem Gefäss mit Torf und Mehl, in welchem Mehlwürmer gezogen wurden, und in pulverisiertem Eidotter $(\infty) \mathrm{P}$.

T'richotarsus Can.

$\dagger$ 146. Tr. intermedius Oudms.

Badener Berge bei Achim: auf Stelis phaeoptera Kby., einer in den Nestern von Osmia leiana Kby. lebenden Hymenoptere (5) 14. 7. 00 . A.

Carpoglyphus Rob.

$\dagger$ 147. C. passularum (Hering).

Vegesack: an Kürbis-Marmelade ( $\infty)$ P.

Labidophorus Kram.

$\dagger$ 148. L. talpae Kram.

Vegesack: auf Sorex vulgaris, Talpa europaea. II, VII, X. P.

$\dagger$ 149. L. platygaster (Mich.).

Ebenda: Nest von Talpa europaea. III. P.

Glycyphagus Hering.

150. GI. domesticus (Degeer).

An altem Rahmkäse, Wohnhaus $(\infty)$ 28. 10. 02. -

Bremen: in einer Schachtel mit Insekten-Detritus $(\propto)$ 9. 00. A. Ebenda: an Möbeln, wo sich die Milben vom Fett der ungereinigten 
Rosshaar - Ausfüllung ernährten ( $\infty)$ P. - Vegesack: auf Sorex vulgaris, Talpa europaea. II, V, VI, VIII. P. ${ }^{1}$ )

$$
\dagger \text { 151. GI. setosus (C. L. Koch). }
$$

Vegesack: in Mehl ( $\left.\begin{array}{ll}1 & \text { o }\end{array}\right)$ P.

\section{$\dagger$ 152. Gl. cadaverum (Schrk.).}

Vegesack: auf Vesperugo serotinus, pipistrellus, Mus silvaticus. II, V, VI, VIII; ${ }^{1}$ ) Nest von Mus minutus (1 nph., 1 우 $)$ 28. 8.96. P.1)

$$
\dagger \text { 153. GI. fustifer Oudms. }
$$

Bremen: an Möbeln. P.

Dermacarus Haller.

$$
\dagger \text { 154. D. arvicolae (Duj.). }
$$

Vegesack: Fuchsberg, auf Arvicola glareolus (7 hypopi). VI; auf Arvicola arvalis. P.

Anoetus Duj.

\section{$\dagger$ 155. A. spiniferus (Mich.).}

Vegesack: (hypopi) auf Sorex vulgaris. II. P.

$\dagger$ 156. A. neglectus Oudms.

Ebenda: (hypopi) auf Necrophorus vespillo, humator. X. P.

157. A. fimetarius (Can. et Berl.).

Auf Aphodius fimetarius, Blockland (2 hypopi) 13. 4. 02.

$$
\text { 158. A. berghi (Jensen). }
$$

1. 9. 01 .

Unter feuchten Steinen, hinter der Anstaltsmauer (1 hypopus)

$$
\begin{aligned}
& \text { Listrophorinae. } \\
& \text { My ocoptes Clap. }
\end{aligned}
$$

\section{$\dagger$ 159. M. musculinus (C. L. Koch).}

Vegesack: auf Mus musculus; „den Myocoptes musculinus habe ich auf seinen Wirten Mus silvaticus und Arvicola arvalis in meinem früheren Wohnort Bremen und dessen nächster Umgegend vergeblich gesucht, hier in Vegesack finde ich ihn dagegen fast auf jedem Exemplar der Hausmaus, das mir in die Hände gerät*. P. (1888).

$$
\begin{aligned}
& \text { Listrophorus Pgst. } \\
+ & \text { 160. L. leuckarti Pgst. }
\end{aligned}
$$

Vegesack: auf Arvicola amphibius. P.

$$
\dagger \text { 161. L. pagenstecheri Haller. }
$$

Vegesack: auf Sciurus vulgaris. P.

1) Nicht ornatus Kram., wie ursprünglich angenommen (Tijdschr. d. Ned. Dierk. Ver. (2). VII, p. 277 und (2) VIII, p. 73). 
Analgesinae.

Pseudalloptes Trouessart.

162. Ps. bisubulatus (Rob.).

Auf Perdix cinerea, Blockland (3 ot, 8 우) 12. 9. 02.

Mégninia Berl.

163. M. cubitalis (Mégn.).

Wie vorige $\left(\begin{array}{lll}2 & \sigma^{\top}\end{array}\right)$ 12. 9. 02.

Proctophyllodes Robin.

$\dagger$ 164. Pr. stylifer (Buchh.).

Vegesack: auf ?. P.

$$
\text { Acarinae (- Sarcoptinae). }
$$

Notoedres Raill.

$\dagger$ 165. N. muris (Mégn.).

Vegesack: auf Mus decumanus (3). P.

Prosopodectes Can.

$\dagger$ 166. Pr. chiropteralis (Trt.).

Vegesack: auf Vesperugo serotinus, pipistrellus. VI, VIII. P.

$\dagger$ 167. Pr. poppei (Oudms.).

Vegesack: auf Vespertilio murinus. P.

Arnhem, 1. Mai 1904.

Göttingen, Oktober 1904.
A. C. Oudemans.

H. Voigts. 


\section{$2 \mathrm{BHL}$ Biodiversity Heritage Library}

Voigts, Hans and Oudemans, A. C. 1905. "Zur Kenntnis der Milben-Fauna von Bremen." Abhandlungen herausgegeben vom Naturwissenschaftlichen Verein zu Bremen 18, 199-252. https://doi.org/10.5962/bhl.part.27528.

View This Item Online: https://www.biodiversitylibrary.org/item/22972

DOI: https://doi.org/10.5962/bhl.part.27528

Permalink: https://www.biodiversitylibrary.org/partpdf/27528

\section{Holding Institution}

New York Botanical Garden, LuEsther T. Mertz Library

\section{Sponsored by}

The LuEsther T Mertz Library, the New York Botanical Garden

\section{Copyright \& Reuse}

Copyright Status: NOT_IN_COPYRIGHT

This document was created from content at the Biodiversity Heritage Library, the world's largest open access digital library for biodiversity literature and archives. Visit BHL at https://www.biodiversitylibrary.org. 